Article (refereed) - postprint

Ward, H.C.; Evans, J.G.; Grimmond, C.S.B.. 2014. Multi-scale sensible heat fluxes in the suburban environment from large-aperture scintillometry and eddy covariance. Boundary-Layer Meteorology, 152 (1). 65-89.

https://doi.org/10.1007/s10546-014-9916-4

(c) Springer Science+Business Media Dordrecht 2014

This version available http://nora.nerc.ac.uk/id/eprint/522496/

NERC has developed NORA to enable users to access research outputs wholly or partially funded by NERC. Copyright and other rights for material on this site are retained by the rights owners. Users should read the terms and conditions of use of this material at http://nora.nerc.ac.uk/policies.html\#access

This document is the author's final manuscript version of the journal article following the peer review process. Some differences between this and the publisher's version may remain. You are advised to consult the publisher's version if you wish to cite from this article.

https://link.springer.com/ 


\title{
Multi-scale sensible heat fluxes in the suburban environment from large aperture scintillometry and eddy covariance
}

\author{
H.C. Ward ${ }^{a, b}$, J.G. Evans ${ }^{a}$, C.S.B. Grimmond ${ }^{\text {b, c }}$ \\ ${ }^{a}$ Centre for Ecology and Hydrology, Wallingford, Oxfordshire, OX10 8BB, UK \\ ${ }^{b}$ Department of Geography, King's College London, London, WC2R 2LS, UK \\ ${ }^{c}$ Department of Meteorology, University of Reading, Reading, RG6 6BB, UK \\ Corresponding author email: helrda@ceh.ac.uk
}

\section{Abstract}

Sensible heat fluxes $\left(Q_{H}\right)$ are determined using scintillometry and eddy covariance over a suburban area. Two large aperture scintillometers provide spatially integrated fluxes across path lengths of $2.8 \mathrm{~km}$ and $5.5 \mathrm{~km}$ over Swindon, UK. The shorter scintillometer path spans newly built residential areas and has an approximate source area of 2-4 $\mathrm{km}^{2}$, whilst the long path extends from the rural outskirts to the town centre and has a source area of around 5-10 $\mathrm{km}^{2}$. These large-scale heat fluxes are compared with local-scale eddy covariance measurements. Clear seasonal trends are revealed by the long duration of this dataset and variability in monthly $Q_{H}$ is related to the meteorological conditions. At shorter time scales the response of $Q_{H}$ to solar radiation often gives rise to close agreement between the measurements, but during times of rapidly changing cloud cover spatial differences in the net radiation $\left(Q^{*}\right)$ coincide with greater differences between heat fluxes. For clear days $Q_{H}$ lags $Q^{*}$, thus the ratio of $Q_{H}$ to $Q^{*}$ increases throughout the day. In summer the observed energy partitioning is related to the vegetation fraction through use of a footprint model. The results demonstrate the value of scintillometry for integrating surface heterogeneity and offer improved understanding of the influence of anthropogenic materials on surface-atmosphere interactions.

\section{Keywords}

Energy balance; Large aperture scintillometer; Seasonality; Sensible heat flux; Urban

\section{Introduction}

Understanding the interactions between the land surface and the atmosphere is central to developing our predictive power in terms of weather forecasting, air quality events, thermal comfort, flood risk and tools for urban design. The surface energy balance has been closely linked to land use and land cover, from studies both within and between cities. This has been achieved largely 
through eddy covariance (EC) measurements at multiple sites in a city (e.g. in Los Angeles

34 (Grimmond et al. 1996), Basel (Christen and Vogt 2004), Łódź (Offerle et al. 2006), Melbourne (Coutts et al. 2007), Montreal (Bergeron and Strachan 2010), Dublin (Keogh et al. 2012), Essen (Weber and Kordowski 2010), Oberhausen (Goldbach and Kuttler 2013) and Helsinki (Nordbo et al. 2013)); and through comparison of measurements from different cities (e.g. Grimmond and Oke $(1995 ; 2002))$. Also, studies at individual sites have combined footprint models and land cover maps to capture differences in the surface cover sampled as the source area of the EC measurement changes with atmospheric conditions (Vesala et al. 2008; Järvi et al. 2012; Goldbach and Kuttler 2013). The derived relations between surface cover and fluxes offer valuable indications of the underlying processes and form a basis for modelling turbulent fluxes (Grimmond and Oke 2002; Järvi et al. 2011; Loridan and Grimmond 2012).

Scintillometry provides a means to estimate fluxes at a much larger scale than eddy covariance, typically of the order of several $\mathrm{km}^{2}$ (Hoedjes et al. 2007; Guyot et al. 2009; Kleissl et al. 2009a). Path-averaging along the electromagnetic beam of the scintillometer means that measurements are inherently spatially integrated, offering a particular advantage over heterogeneous surfaces (Beyrich et al. 2002; Meijninger et al. 2002b; Evans 2009; Samain et al. 2011a). Despite the complexity of the urban surface, patches of impervious land cover (roads, car parks, paved areas) adjacent to green spaces (parks, gardens) are not very different to the juxtaposition of fields containing differently ripening and senescing crops in mixed agricultural landscapes. In such studies, measuring sufficiently high above the surface ensures the influences of surface heterogeneity are well-blended at the height of the measurement and reliable fluxes can be obtained (Meijninger et al. 2002b; Ezzahar et al. 2007). In addition to the increased spatial representativeness of such large-area measurements, their increased scale facilitates comparison with satellite remote sensing products or land-surface et al. (2011b), Steeneveld et al. (2011) and Maronga et al. (2013).

The use of scintillometers in urban environments can be divided into two groups: (a) studies involving small aperture instruments, usually deployed within or near the top of the roughness sublayer on path lengths of the order of 100 m, e.g. in Tokyo (Kanda et al. 2002), Basel (Roth et al. 2006) and London (Pauscher 2010); and (b) studies over much longer path lengths (500 m - $10 \mathrm{~km}$ ) using large aperture scintillometers. This study uses large aperture scintillometry. The much larger sampling volume enables robust retrieval of turbulence statistics and the measurement sensitivity is 
greatest near the centre of the path, away from the instruments and their mounting structures, such that the influence of locally-produced turbulence around these structures has minimal impact on the measurements. Furthermore, direct access to the measurement area is not required - an electromagnetic beam is simply transmitted high above the surface - unlike point measurements requiring in situ mounting. This remote sensing capability makes the scintillometry technique particularly valuable in the urban environment.

There are an increasing number of studies using large aperture scintillometry in urban areas. Lagouarde et al. (2006) present results from a three week trial in summer 2001 in which two large aperture scintillometers were used over Marseille. Other studies include work in London (Gouvea and Grimmond 2010), Nantes (Mestayer et al. 2011), Łódź (Zieliński et al. 2012) and Helsinki (Wood and Järvi 2012).

To date, the use of large aperture scintillometry in urban areas has been to derive the sensible heat flux. In order to directly estimate the latent heat flux, a second scintillometer of longer wavelength is required (Hill et al. 1988; Andreas 1989), however these are not yet commercially available. Hence there are only a handful of two-wavelength studies documented (Kohsiek and Herben 1983; Green et al. 2001; Meijninger et al. 2002a; Meijninger et al. 2006; Evans 2009). A millimetre-wave scintillometer was installed alongside one of the infrared scintillometers used in this study. These first two-wavelength results from the urban environment are presented in two companion papers (Ward et al. in preparation a,b).

The goal of the work presented here is to investigate the influence of the surface on sensible heat fluxes across different spatial and temporal scales in the suburban environment. Eddy covariance measurements are analysed together with results from large aperture scintillometers installed on $2.8 \mathrm{~km}$ and $5.5 \mathrm{~km}$ paths in Swindon, UK. The two year study period enables analysis of seasonal and inter-annual patterns (Sect. 3.1) as well as the short-term response of heat fluxes to solar radiation (Sect. 3.2). Consideration is given to the experimental uncertainties, including the representativeness of point measurements required as inputs for scintillometry algorithms (Sect. 2.3) and the observational challenges associated with urban environments. The contributions of different land cover classes are related to the observations at each scale by applying a footprint model (Sect. 3.3). 


\section{Methodology}

96

97

98

99

100

101

102

103

104

105

106

107

108

109

\subsection{Derivation of the sensible heat flux from single-wavelength scintillometry}

Scintillometers measure the intensity of an electromagnetic beam after propagation through the turbulent atmosphere. Changes in beam intensity are related to the strength of turbulence and can be converted to the structure parameter of the refractive index of air $\left(C_{n}^{2}\right)$. First, these refractive index fluctuations must be related to temperature fluctuations,

$$
C_{T}^{2} \approx \frac{T^{2}}{A_{T}^{2}} C_{n}^{2}
$$

where $C_{T}^{2}$ is the temperature structure parameter and $A_{T}$ is the structure parameter coefficient which depends on temperature $(T)$, pressure $(p)$ and weakly on humidity (Hill et al. 1980; Andreas 1988; Ward et al. 2013b). The Bowen ratio ( $\beta$ ) correction given by Wesely (1976) (see Moene (2003) for full details and a discussion) is not implemented in Equation 1 because $\beta$ is not known a priori. The effect of this is discussed in Sect. 2.3.

The conversion from structure parameters to fluxes entails iteration of similarity functions, $f_{M O}(\zeta)$, using Monin-Obukhov similarity theory (MOST) and the effective height of the scintillometer, $z_{e f}$, the wind speed, $U$ (which is measured at height $z_{U}$ ), displacement height, $z_{d}$, and aerodynamic roughness length, $z_{0}$. Commonly used forms of the similarity functions are

$$
f_{M O}(\zeta)=c_{T 1}\left(1-c_{T 2} \zeta\right)^{-2 / 3}
$$

for unstable conditions and

$$
f_{M O}(\zeta)=c_{T 1}\left(1-c_{T 3} \zeta^{2 / 3}\right)
$$

for stable conditions. The stability variable $\zeta$ is given by $\left(z_{m}-z_{d}\right) / L_{O b}$, where $L_{O b}$ is the Obukhov length and $z_{m}$ the measurement height, or $z_{e f} / L_{O b}$ when $z_{e f}$ has been calculated incorporating the displacement height (Hartogensis et al. 2003). Different values of the empirically derived constants $c_{T 1-3}$ are used in the literature (Andreas 1988; Hill et al. 1992), and alternative functional forms appear, e.g. Thiermann and Grassl (1992). The Wyngaard (1973) values were adjusted by Andreas (1988) to give $c_{T 1}=4.9, c_{T 2}=6.1$ and $c_{T 3}=2.2$ (hereafter An88). De Bruin et al. (1993) found $c_{T 1}=4.9$, $c_{T 2}=9$ and $c_{T 3}=0$ (hereafter DB93). These similarity functions relate the temperature structure parameter to the temperature scaling variable $\left(T_{*}\right)$, 
The friction velocity, $u_{*}$, is estimated from measured wind speed assuming a logarithmic wind profile adjusted for stability and a value for the roughness length (e.g. Stull (1988)). The wind profile equation is solved iteratively with

$$
L_{O b}=\frac{u_{*}^{2} T}{g \kappa_{v} T_{*}},
$$

where $g$ is the acceleration due to gravity and $\kappa_{v}$ is the von Kármán constant (0.4). Note that this equation for $L_{O b}$ neglects the buoyancy correction. Finally, the sensible heat flux is obtained using

$$
Q_{H}=-\rho c_{p} u_{*} T_{*},
$$

where $\rho$ is the density of air and $c_{p}$ the specific heat capacity at constant pressure. In the following, $Q_{H_{-} B L S}$ and $Q_{H_{-} L A S}$ are used to denote the sensible heat flux for the $5.5 \mathrm{~km}$ path and $2.8 \mathrm{~km}$ path, respectively (Sect. 2.2). The sensible heat flux from the EC station is denoted $Q_{H_{-} E C}$.

One drawback of scintillometry is that the sign of the heat flux is unknown and must be assigned based on other information. Following a comparison of possible algorithms, Samain et al. (2012) recommended using an algorithm based on the minima in the diurnal cycle of $C_{n}^{2}$ to indicate a transition of stability. We follow a similar methodology here, which has the key advantage that it is based on path-averaged information.

\subsection{Site description and experimental details}

This study took place in Swindon (population 175 000), situated $120 \mathrm{~km}$ west of London (top right, Fig. 1). Typical of the UK suburban landscape, Swindon consists mainly of residential areas with houses of varying ages extending outwards from the town centre, interspersed with greenspace, small parades of shops and institutional buildings. Larger industrial and commercial zones are mostly situated towards the edges of the development. The town centre comprises commercial areas, with some pedestrianized streets, offices, public buildings and transport hubs. Building density in the town centre is greater than in the surrounding suburbs and buildings are taller, larger and more variable in height. Outside of the urban core the buildings are more uniform, houses are mostly 1-3 storeys, semi-detached or terraced and usually have at least a small garden. There are a few small blocks of flats (4-5 storeys) and larger warehouses in industrial areas. Trees are of a similar height to the buildings and found mostly in undeveloped green corridors between residential areas, along 
roadsides and in gardens. The area is relatively well vegetated (cover fraction 53\%), largely due to the prevalence of grassed areas: parks, playing fields, green corridors, gardens, verges and a large nature reserve near the centre of the study area (Fig. 1).

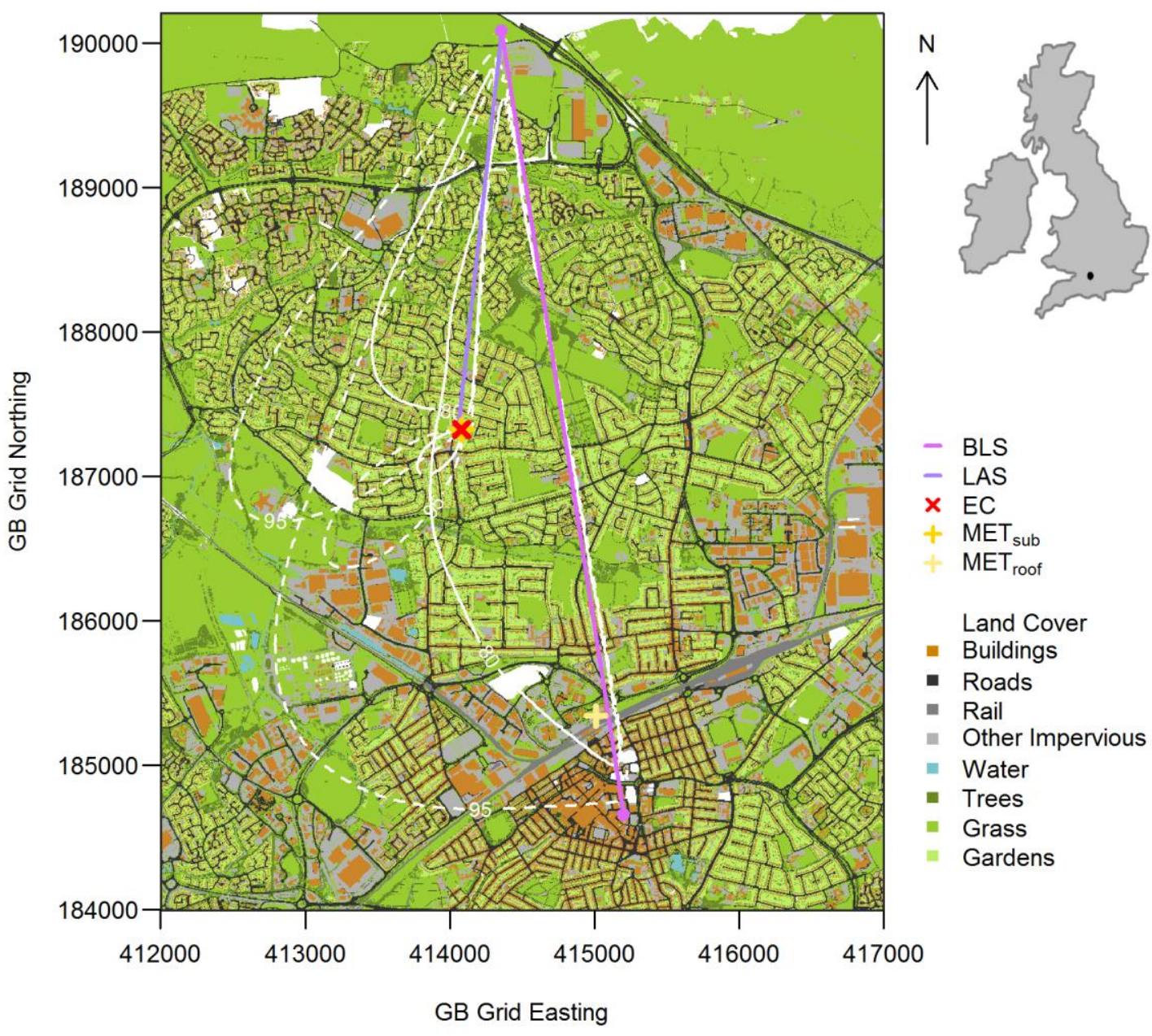

Fig. 1 Land cover surrounding the two scintillometer paths (BLS and LAS), eddy covariance station (EC) and two meteorological stations ( $\mathrm{MET}_{\text {sub }}$ and $\mathrm{MET}_{\text {rooff }}$. Example footprints for typical atmospheric conditions (wind direction $=225^{\circ}$, $L_{O b}=-200 \mathrm{~m}, u_{*}=0.5 \mathrm{~m} \mathrm{~s}^{-1}$ and $\sigma_{v}=0.9 \mathrm{~m} \mathrm{~s}^{-1}$ ) are indicated by the cumulative source area: the region within the solid (dashed) line contributes $80 \%$ (95\%) to the measured flux. The location of Swindon within the British Isles is shown (top right). Details of the land cover classification are given in the text. Where land cover data were unavailable areas are left unclassified (white).

Observations at multiple scales are achieved through a combination of the eddy covariance technique and two scintillometer paths. The largest measurement scale reaches between the town centre and the rural fringe at the northern edge of the settlement: an infrared scintillometer, the 
BLS900 (Scintec, Rottenburg, Germany), was installed on a $5.5 \mathrm{~km}$ path orientated approximately north-south. A second infrared scintillometer, a LAS 150 (Kipp and Zonen, Delft, The Netherlands), was aligned on a shorter path of length $2.8 \mathrm{~km}$. This path is located over relatively recently developed suburbs (in the last 20 years or so) 3-5 km north of the town centre. Both are large aperture scintillometers operating at a wavelength of $880 \mathrm{~nm}$. Although LAS is an abbreviation for large aperture scintillometer, in this study BLS is used to denote the scintillometer on the long path and LAS the scintillometer on the short path. The EC system was installed approximately $3 \mathrm{~km}$ north of the town centre, close to the middle of the long path.

Footprint models can be used to aid the interpretation of observed fluxes by relating them to the probable area of the surface that influenced the measurements. Although some of the assumptions may be challenged by complex environments, footprint models have been used successfully in urban areas (Schmid et al. 1991; Järvi et al. 2009; Hiller et al. 2011), providing measurements are made at sufficient height that the influences of individual obstacles or heterogeneities are averaged out. Meijninger et al. (2002b) extended footprint theory to scintillometers by combining source areas calculated for a single point measurement with the scintillometer path weighting function. This has since been adopted by other studies (Meijninger et al. 2006; Hoedjes et al. 2007; Samain et al. 2011a; Evans et al. 2012; Liu et al. 2013). A range of footprint models exist; here we use the analytical model of Hsieh et al. (2000) and assume the lateral dispersion is Gaussian (Schmid 1994; Detto et al. 2006).

Results of the footprint model for each of the three systems are shown in Fig. 1 for typical atmospheric conditions (wind direction $=225^{\circ}, L_{O b}=-200 \mathrm{~m}, u_{*}=0.5 \mathrm{~m} \mathrm{~s}^{-1}$ and standard deviation of lateral wind $\sigma_{v}=0.9 \mathrm{~m} \mathrm{~s}^{-1}$ ). Source areas vary depending on atmospheric conditions and wind direction, as well as measurement height and surface roughness. The difference in measurement scales is apparent. The sizes of the areas contributing $80 \%(95 \%)$ of the observed fluxes are approximately $0.06,1.0$ and $3.0 \mathrm{~km}^{2}\left(0.5,3.0\right.$ and $\left.7.5 \mathrm{~km}^{2}\right)$ for the EC, LAS and BLS, respectively. The size of the footprints increases with stability.

Beam heights, land cover and building and tree height were obtained using a spatial database incorporating surface cover information (OS MasterMap 2010 (C) Crown Copyright), a digital terrain model and digital surface model from lidar (2007, CInfoterra Ltd) and aerial photography (2009, (CGeoPerspectives). For this study a spatial resolution of $5 \mathrm{~m}$ was used, further details are given in Ward et al. (2013a). Some of the residential area at the far north-west of the study area has very recently been completed, with some ongoing development of the rural outskirts during the study 
for the LAS path, when winds are from the west or north-west and in stable conditions, as this recent development has not yet been incorporated in the spatial database.

The roughness length for momentum was estimated based on the mean height of the roughness elements $\left(z_{H}\right)$ within the area influencing the measurements using the approximation $z_{0}=0.1 z_{H}$ (Garratt 1992). The resulting values (Table 1) are reasonable based on comparison with the literature (Grimmond and Oke 1999), however there is appreciable uncertainty associated with this (and other) methods (Sect. 3.1). The zero plane displacement height, $z_{d}$, is estimated at $0.7 z_{H}$ and incorporated into the effective height calculation for the scintillometers, after Hartogensis et al. (2003) (their equation 15).

Both infrared scintillometer transmitters were installed on a telecommunications mast at the northern edge of the suburbs at $27.9 \mathrm{~m}$ (BLS) and $26.6 \mathrm{~m}$ (LAS) above ground level. The LAS receiver was bolted to a $1.7 \mathrm{~m}$ high post at the same property as the EC mast, whilst the BLS receiver was mounted on a building in the town centre at $26.2 \mathrm{~m}$. The combination of the topography (Fig. 2), mounting on existing structures and the path weighting provides sufficient beam height for the scintillometers to be above the blending height (which is estimated to be between 15 and $30 \mathrm{~m}$ (Pasquill 1974; Garratt 1978)). The blending height will be larger above landscapes with larger scale heterogeneity (e.g. Wood and Mason (1991)), or may not exist at all once the scale of heterogeneity exceeds the boundary layer height (Maronga and Raasch 2013). With these limitations in mind, the Swindon sites were selected such that the patches of different land cover within the footprints are, for the most part, reasonably small (100 - $300 \mathrm{~m}$ or less). 


\begin{tabular}{|c|c|c|c|c|c|c|c|c|}
\hline Instrumentation & Dates & Location & $z_{m}[\mathrm{~m}]$ & $\begin{array}{c}z_{e f} \\
{[\mathrm{~m}]}\end{array}$ & $\begin{array}{c}\text { Path } \\
\text { length }[\mathrm{m}]\end{array}$ & $\begin{array}{c}\text { Bearing } \\
{\left[{ }^{\circ}\right]}\end{array}$ & $\begin{array}{c}z_{0} \\
{[\mathrm{~m}]}\end{array}$ & $\begin{array}{c}z_{d} \\
{[\mathrm{~m}]}\end{array}$ \\
\hline BLS & $\begin{array}{l}12 \text { Jan } 2011- \\
31 \text { Dec } 2012\end{array}$ & $\begin{array}{c}51^{\circ} 366^{\prime} 33.9^{\prime \prime} \mathrm{N} \\
1^{\circ} 47^{\prime} 38.6^{\prime \prime} \mathrm{W}(\mathrm{Tx}) \\
51^{\circ} 33^{\prime} 38.1^{\prime \prime} \mathrm{N} \\
1^{\circ} 46^{\prime} 55.3^{\prime \prime} \mathrm{W}(\mathrm{Rx})\end{array}$ & 44.3 & 45.0 & 5492 & 170 & 0.7 & 4.9 \\
\hline LAS & $\begin{array}{l}22 \text { Jun } 2011 \text { - } \\
31 \text { Dec } 2012\end{array}$ & $\begin{array}{c}51^{\circ} 36 ' 33.9^{\prime \prime} \mathrm{N} \\
1^{\circ} 47^{\prime} 38.6^{\prime \prime} \mathrm{W}(\mathrm{Tx}) \\
51^{\circ} 35^{\prime} 4.9^{\prime \prime} \mathrm{N} \\
1^{\circ} 47^{\prime} 53.0^{\prime \prime} \mathrm{W}(\mathrm{Rx})\end{array}$ & 32.4 & 35.9 & 2761 & 184 & 0.6 & 4.5 \\
\hline EC & $\begin{array}{c}09 \text { May } 2011- \\
31 \text { Dec } 2012\end{array}$ & $\begin{array}{l}51^{\circ} 35^{\prime} 4.6^{\prime \prime} \mathrm{N} \\
1^{\circ} 47^{\prime} 53.2^{\prime \prime} \mathrm{W}\end{array}$ & 12.5 & - & - & - & 0.5 & 3.5 \\
\hline $\mathrm{MET}_{\text {sub }}$ & $\begin{array}{c}09 \text { May } 2011- \\
31 \text { Dec } 2012\end{array}$ & $\begin{array}{l}51^{\circ} 35^{\prime} 4.6^{\prime \prime} \mathrm{N} \\
1^{\circ} 47^{\prime} 53.2^{\prime \prime} \mathrm{W}\end{array}$ & $\begin{array}{l}10.6 \text { (WXT) } \\
10.1 \text { (NR01) }\end{array}$ & - & - & - & 0.5 & 3.5 \\
\hline MET $_{\text {roof }} *$ & $\begin{array}{l}01 \text { Jan } 2011- \\
31 \text { Dec } 2012\end{array}$ & $\begin{array}{l}51^{\circ} 34^{\prime} 0.3^{\prime \prime} \mathrm{N} \\
1^{\circ} 47^{\prime} 5.3^{\prime \prime} \mathrm{W}\end{array}$ & $\begin{array}{l}2.0(\mathrm{WXT}) \\
1.1 \text { (NR01) }\end{array}$ & - & - & - & - & - \\
\hline
\end{tabular}

Table 1 Details of the instrumental setup. Tx denotes transmitter, Rx receiver. For the scintillometers the mean heights of the beams above the surface $\left(z_{m}\right)$ and the effective measurement heights $\left(z_{e f}\right)$ are given. The date range refers to the data used here. *For $\mathrm{MET}_{\text {roof }}$ the heights above the roof surface are given; $z_{0}$ and $z_{d}$ were not calculated for this site. 

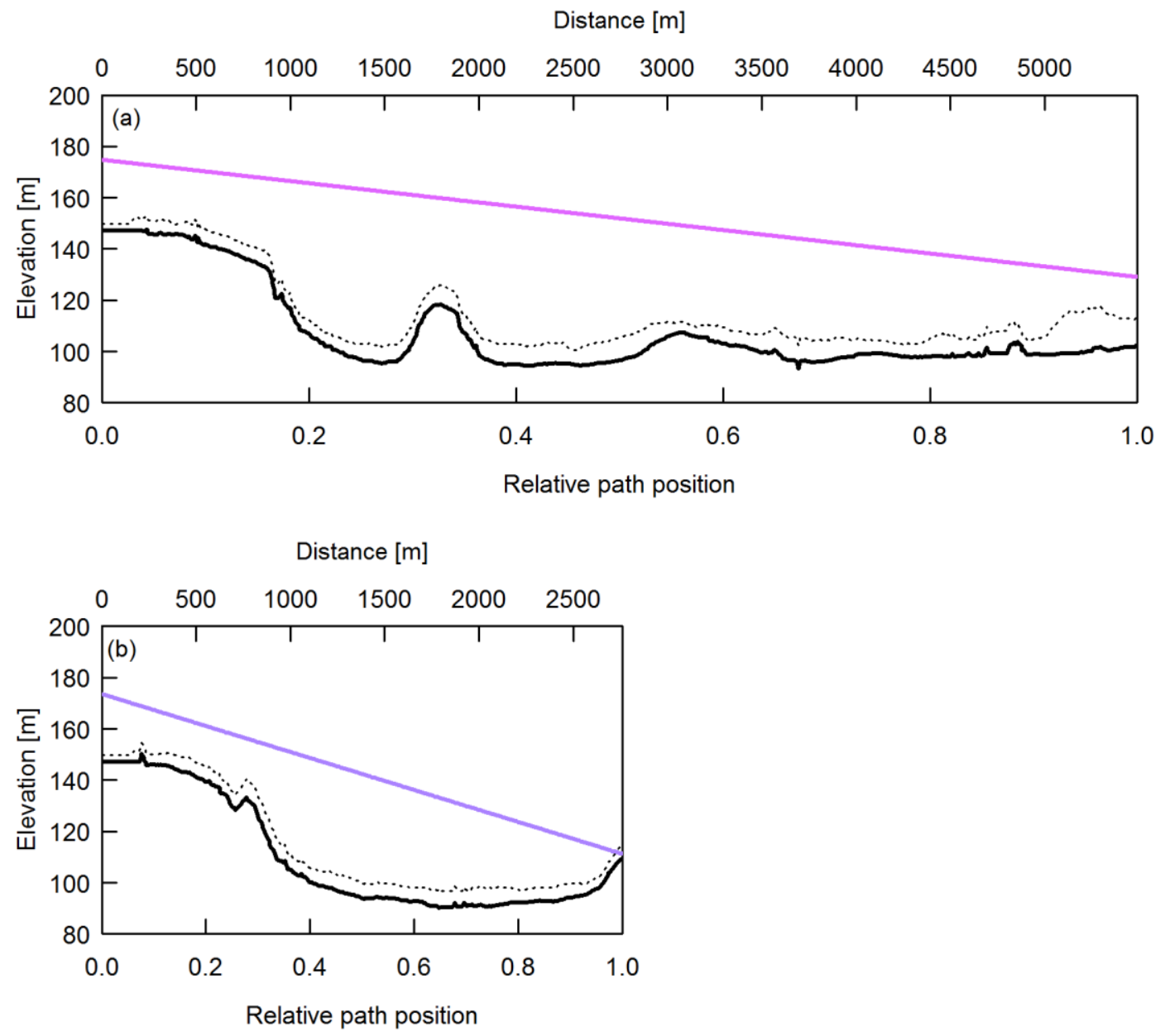

Fig. 2 Cross section of the topography (solid black line) and mean obstacle height (dotted line; buildings and trees within a radius of $100 \mathrm{~m}$ ) along the (a) BLS and (b) LAS paths (coloured lines).

A CR5000 datalogger (Campbell Scientific Ltd., Loughborough, UK) sampled the intensity of the received LAS beam at $500 \mathrm{~Hz}$ and measured the $C_{n}{ }^{2}$ signal (calculated onboard the instrument and stored as a logarithm) every second which was then output at $1 \mathrm{~min}$ intervals and these were averaged to $10 \mathrm{~min}$. For the BLS, the mean and standard deviation of the beam intensity of each disk (the BLS900 is a dual disk instrument with two transmitting apertures) were obtained from the supplied signal processing unit at $30 \mathrm{~s}$ intervals, then converted to log-amplitude variances and $C_{n}{ }^{2}$ and averaged up to $10 \mathrm{~min}$. Data from a single disk are presented here.

The EC system consists of a sonic anemometer (R3, Gill Instruments Ltd., Lymington, UK) and an open-path infrared gas analyser (LI-7500, LI-COR Biosciences, Lincoln, USA) at a height of $12.5 \mathrm{~m}$. As this is 2-3 times the height of the surrounding buildings and trees, it is therefore sufficiently high to deliver fluxes representative of the local-scale. Data were processed using EddyPro (LI-COR) 
following conventional procedures. Further details of the EC measurements can be found in Ward et al. (2013a).

Meteorological instruments were installed on the same mast as the EC equipment (denoted $\left.\mathrm{MET}_{\text {sub }}\right)$. A second set of meteorological data were collected at a rooftop site close to the town centre ( $\mathrm{MET}_{\text {roof }}$ ). Both stations included a four-component radiometer (NR01, Hukseflux, Delft, The Netherlands), automatic weather station (WXT510, Vaisala, Helsinki, Finland) and tipping bucket rain gauge (0.2 mm tip, Casella CEL, Bedford, UK). At MET sub, the radiometer was installed at a height of $10.1 \mathrm{~m}$ so that the downward-facing field of view comprises a mixture of surfaces: grass lawns and verges, road, pavement, hedges and small trees, bare soil, gravel, roofs of garages, small sheds and single-storey extensions and walls (brick and painted). At $\mathrm{MET}_{\text {roof, }}$ the radiometer was installed at 1.1 $\mathrm{m}$ above the roof surface made of grey synthetic material and black rubber matting. Additionally at $\mathrm{MET}_{\text {roof, }}$ a heat flux plate (HFP01, Hukseflux) was installed between the roof surface and rubber sheet, providing an approximation of the change in storage through the roof. At both sites the meteorological data were logged at 1 min intervals (CR1000, Campbell Scientific Ltd.) and subsequently averaged to obtain $10 \mathrm{~min}$ resolution for calculation of the scintillometer fluxes or 30 min for comparison with EC fluxes. The $10 \mathrm{~min}$ scintillometer fluxes were also averaged to $30 \mathrm{~min}$ for comparison with EC results. Details of the observational setup are summarized in Table 1.

To provide nearly continuous auxiliary data required for scintillometry processing, results from the two meteorological stations were combined. When available, data from $\mathrm{MET}_{\text {sub }}$ are used as the siting of this station is more appropriate. Based on the regression of concurrent data (9 May 2011 31 Dec 2012), temperature, relative humidity (RH), pressure and wind speed at $\mathrm{MET}_{\text {roof }}$ were adjusted to gap-fill the combined dataset, including the period prior to installation of $\mathrm{MET}_{\text {sub }}$ on 9th May 2011. This is considered further in Sect. 2.3.

All data were subject to quality control routines. Data were removed at times of known instrument malfunction. Meteorological data were excluded when they (or their standard deviations) fell outside physically reasonable thresholds. Quality control of the scintillometry data included rejecting times when the received signal intensity dropped below half of the value in clear conditions, which usually indicated rain or fog. Data points neighbouring those that failed the intensity check were also removed. Out of the total data collected, $84 \%$ of BLS and $82 \%$ of LAS data (10 $\mathrm{min}$ ) remained for analysis. 
the BLS data and $0.2 \%$ of the LAS data might be expected to suffer from saturation. Overall, the correction increased $C_{n}{ }^{2}$ by $4 \%$ and $1 \%$ for the BLS and LAS respectively (naturally the corrections are larger with increased scintillation and rise to $8 \%$ and $2 \%$ for the midday periods).

Recent studies have indicated sometimes severe discrepancies between certain scintillometers, in particular the LAS 150 model (Kleissl et al. 2008), whereas the BLS900 model tends to give more reproducible results (Kleissl et al. 2009b). Prior to deployment in Swindon, the LAS and BLS were run alongside each other at a fairly homogenous grass test site at Chilbolton Observatory, Hampshire, UK (17 April 2010 - 25 May 2010). Observed $C_{n}^{2}$ ranged between $10^{-16} \mathrm{~m}^{-2 / 3}$ and $10^{-12} \mathrm{~m}^{-2 / 3}$, which spans the range of values observed for the Swindon paths. Results suggested the response of the LAS is reasonable but compared to the BLS $C_{n}{ }^{2}$ is overestimated by $9.8 \%$. This adjustment has been applied to the LAS $C_{n}{ }^{2}$ for the Swindon data. As a result of these comparisons (e.g. Kleissl et al. (2008; 2009b), Van Kesteren and Hartogensis (2011)), Kipp and Zonen have updated their original LAS 150 instrument to a LAS MkII model (Mustchin et al. 2013).

\subsection{Assessment of the input meteorological data}

First, the suitability of the combined meteorological input data used to process the scintillometry fluxes is considered. To calculate $Q_{H}$ from single-wavelength scintillometry, air temperature, pressure and humidity are required to first obtain the structure parameter of temperature, $C_{T}^{2}$. Both $T$ and $\mathrm{RH}$ are similar between the $\mathrm{MET}_{\text {sub }}$ and unadjusted $\mathrm{MET}_{\text {roof }}$ sites. The regression slopes are within $3 \%$ and there is high correlation $\left(r^{2}>0.98\right)$. Sensitivity of $Q_{H}$ to these input meteorological variables is small (Hartogensis et al. 2003) and indeed these very small differences have minimal impact on the fluxes. The average difference in $Q_{H}$ is $<0.5 \%$ when calculated using $T, \mathrm{RH}$ and $p$ from each site. Use of this combined dataset is therefore judged unproblematic and to be a sufficiently accurate representation of $T, \mathrm{RH}$ and $p$ across the study area.

An initial estimate of the Bowen ratio is recommended to account for the contribution of humidity and combined temperature-humidity fluctuations to optical $C_{n}{ }^{2}$ (Wesely 1976). Usually the value of $\beta$ is arrived at iteratively through incorporation of the available energy (e.g. Meijninger et al. (2002b)). However, estimating the available energy is challenging in urban areas as the net storage heat flux $\left(\Delta Q_{S}\right)$ plays a more significant role in the energy balance than for most rural areas (e.g. grassed or agricultural land), yet it is very difficult to measure directly (Offerle et al. 2005; Roberts et al. 2006). Other (rural) studies have used $\beta$ measured at a nearby station (Hoedjes et al. 2002; Samain et al. 2011a) or have calculated $Q_{H}$ using a series of values of $\beta$ (Meijninger and De Bruin 2000). When $\beta$ is expected to be large (e.g. $>0.6$ for Chehbouni et al. (2000b); > 1 for Moene (2003)) 
the correction may be neglected. Given the uncertainty in estimating the available energy and the lack of representative EC data across the whole study area, the Bowen ratio correction has not been applied for the results presented here. The potential impact is an average overestimation in $Q_{H}$ from the scintillometers of less than $5 \%$ for $\beta>1$, and less than $10 \%$ for $\beta=0.5$. For the $\mathrm{BLS}$, the $C_{T}^{2}$ values here were found to be within around $6 \%$ of the $C_{T}^{2}$ values calculated incorporating data from the millimetre-wave scintillometer (Sect. 1), which do not require a Bowen ratio correction (see Ward et al. (in preparation b) for details).

To process scintillometry data, the friction velocity is usually estimated from wind speed measured at a single point and adjusted to beam height using the logarithmic profile accounting for stability. As with the other meteorological inputs, wind speed from $\mathrm{MET}_{\text {roof }}$ was adjusted to produce the combined dataset with optimum availability of input data. Concurrent $Q_{H}$ values calculated using the $\mathrm{MET}_{\text {sub }}$ wind speed or the adjusted $\mathrm{MET}_{\text {roof }}$ wind speed differ by less than $3 \%, r^{2}$ is high (0.98) and there is little scatter (root mean squared error, RMSE $<10 \mathrm{~W} \mathrm{~m}^{-2}$ ).

The dual-disk design of the BLS900 enables estimation of the path-averaged crosswind, i.e. the component of the wind speed perpendicular to the scintillometer path. To check that the point measurements of wind speed were a realistic proxy for the wind field over the scintillometer source area, a comparison was made between the BLS crosswind speed and the equivalent crosswind speed calculated using wind speed and direction from $\mathrm{MET}_{\text {sub }}$ and scaled to the effective height of the BLS using stability from the EC station. Overall the crosswind estimates displayed similar trends across a range of wind speeds and directions. The high correlation obtained $\left(r^{2}=0.922\right)$ implies that these point measurements generally capture the variability of the wind field at the larger scale and gives confidence in their use in processing the scintillometry data.

\section{Analysis of sensible heat fluxes}

\subsection{Assessment of seasonal cycles and annual variations}

Large-area sensible heat fluxes from the $5.5 \mathrm{~km}$ scintillometer path are presented for two years (2011-12), alongside 18 months of data from the shorter $2.8 \mathrm{~km}$ scintillometer path and almost 20 months of eddy covariance data (Fig. 3). The annual cycle is evident, with mean daily (24 h) $Q_{H}$ reaching a maximum in early summer (May-June in 2011, May in 2012) and minimum in December. In December, average $Q_{H}$ is negative even during daytime (defined as times when incoming shortwave radiation $K_{\downarrow}>5 \mathrm{~W} \mathrm{~m}^{-2}$, see Fig. 3b) as the typical diurnal course of $Q_{H}$ becomes positive only for a few hours around midday (Fig. 4). This behaviour is observed consistently across the three datasets and in both years but contrasts with the majority of urban studies in more built-up areas, 
where greater heat release from storage and anthropogenic activity can maintain a positive sensible heat flux all year round (Offerle et al. 2005; Kotthaus and Grimmond in press-a). For two sites in Oberhausen, Germany, Goldbach and Kuttler (2013) found $Q_{H}$ to be positive for most of the daytime throughout the year at their urban site, whereas their suburban site exhibits similar behaviour to Swindon. Besides the smaller storage and anthropogenic heat flux in suburban areas, more of the available energy is partitioned into evaporation, owing to increased moisture availability from soil surfaces and greater total evapotranspiration from a larger vegetation fraction.

Within the trends of the expected annual cycle, there are notable differences between the two years studied. Peak $Q_{H}$ is larger in summer 2011 compared to 2012 and month-to-month variation is smaller in 2011. Broadly speaking, much of 2011 was under threat of drought, with dry soil moisture conditions and depleted ground water supplies. Despite frequent rain and very few clear sky days the annual rainfall total was $530 \mathrm{~mm}$ compared to the average $780 \mathrm{~mm}$ for southern England ${ }^{1}$. Dry conditions continued through early spring 2012, until early April. Very wet weather followed and remained throughout 2012 (total rainfall $1020 \mathrm{~mm}$ ), with brief drier and warmer spells in late July and early September.

June 2012 was particularly wet and cloudy (sunshine hours were only $70 \%$ of normal ${ }^{1}$; mean daytime $K_{\downarrow}$ was $174 \mathrm{~W} \mathrm{~m}^{-2}$ in 2012 compared to $212 \mathrm{~W} \mathrm{~m}^{-2}$ in 2011). Monthly mean daily $Q_{H}$ was 19\%, 34\% and 31\% lower than in June 2011 for the BLS, LAS and EC, respectively. August 2012 also had a notably lower $Q_{H}$ during daytime compared to 2011 (also shown in Fig. 4), despite similar radiative energy inputs in both years. A long dry spell and generally sunny weather in September 2012 allowed surfaces to dry out and $Q_{H}$ to increase, resulting in a larger average value than for the previous month. Large negative nocturnal $Q_{H_{-} B L S}$ in February 2011 means the daily (24 h) average is negative, whereas high $Q^{*}$ and high daytime $Q_{H_{-} \text {BLS }}$ in 2012 contribute to a positive $24 \mathrm{~h}$ average in 2012 (Fig. 3).

\footnotetext{
${ }^{1}$ Met Office climate statistics (1971-2000), http://www.metoffice.gov.uk/climate, last accessed 29 March 2013
} 

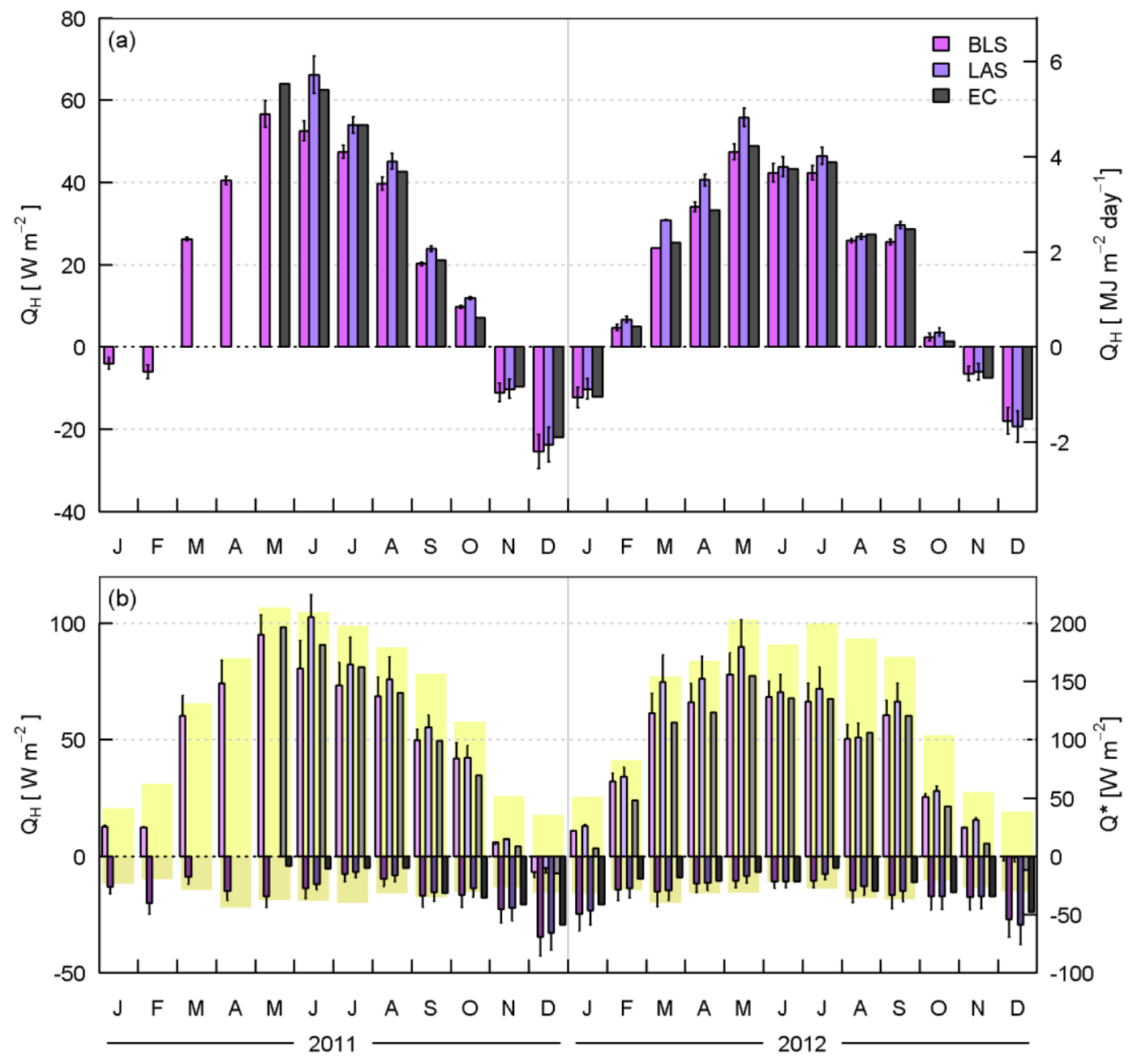

357

358 Fig. 3 Monthly mean sensible heat flux observations from scintillometry (BLS and LAS) and eddy covariance (EC) for all available data (a) over $24 \mathrm{~h}$ and (b) separated into day $\left(K_{\downarrow}>5 \mathrm{~W} \mathrm{~m}^{-2}\right)$ and night times. Partial months in relation to the installation dates (Table 1) are January 2011 (BLS), May 2011 (EC) and June 2011 (LAS, note only 4 days of data due to an instrument fault). Error bars indicate the impact on the scintillometer fluxes of altering the input roughness length by \pm 0.2 $\mathrm{m}$ (a) or using the similarity functions of De Bruin et al. (1993) (b). The net radiation is indicated by shading (b, right-hand axis). 


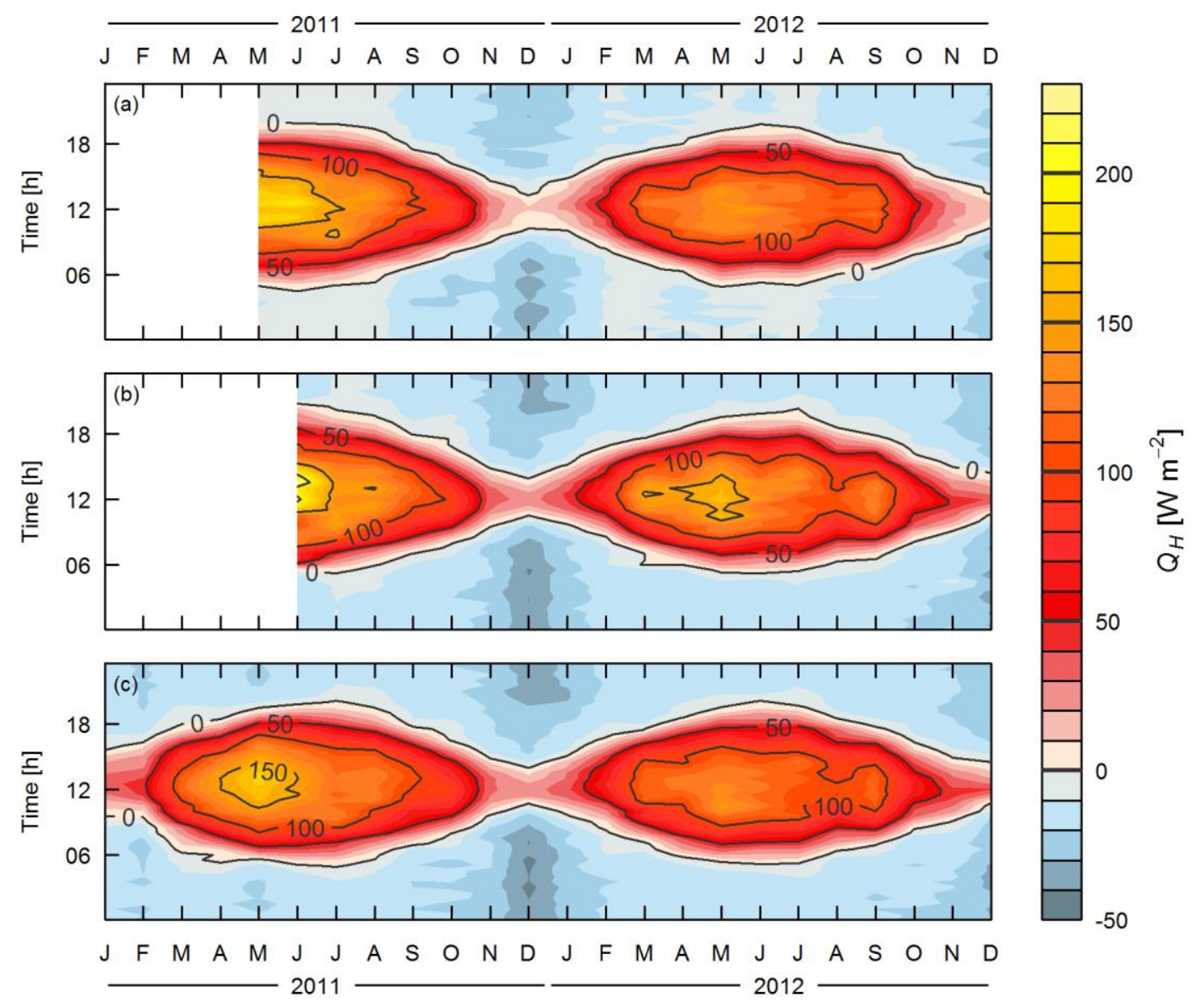

Fig. 4 Temporal variation of monthly mean diurnal cycles of sensible heat fluxes from (a) eddy covariance, (b) the LAS and (c) the BLS.

Overall there is remarkably good agreement across the three datasets, which capture seasonal similarities and inter-annual variability. The different source areas of each instrument, and that the BLS measures across a large proportion of northern Swindon, suggest that these trends are local-tocity-scale responses to regional weather variability. Furthermore, this agreement implies that any bias in the monthly averages due to the effect of the wind direction distribution on the measurement footprints is outweighed by the changes in surface conditions, prevailing weather and the resulting surface-atmosphere interactions. Given the much smaller source area of the EC technique compared to scintillometry, it is reasonable to expect that heterogeneity of the surface has a larger influence on the EC observations than the scintillometry observations (Sect. 3.3).

The LAS tends to give the largest $Q_{H}$, particularly during daytime, compared to both EC and the BLS. In summer 2012 the EC and BLS average values do not reach above $150 \mathrm{~W} \mathrm{~m}^{-2}$, in contrast to $Q_{H_{-} L A S}$ (Fig. 4). During winter months (November 2011-January 2012) and at night the BLS gives the 
largest fluxes. Daily average $Q_{H_{-} E C}$ often lies between the two scintillometer averages but during winter (November-December 2011, December 2012) and at night the scintillometers tend to give larger magnitude $Q_{H}$. This can also be seen in Fig. 4: the absolute size of $Q_{H}$ from the scintillometers is larger (e.g. around transition times in December), whether positive or negative, whereas EC values are much closer to zero. Larger scintillometer fluxes in neutral-to-stable conditions may reflect the performance of the similarity functions (Sect. 3.2).

The widely implemented similarity functions of Andreas (1988) were used here. Using the De Bruin et al. (1993) similarity functions instead increases $Q_{H}$ by about $13-14 \%$ (bars in Fig. 3b). This is similar to results in Marseille (Lagouarde et al. 2006) and within the $10-15 \%$ range given by Beyrich et al. (2012). The large uncertainty introduced by the choice of similarity function is a major limitation of the scintillometry technique across all environments; it is not confined to urban sites although there is the added question of whether functions developed over homogeneous terrain should be applied to more heterogeneous locations. Kanda et al. (2002) and Roth et al. (2006) both derived 'urban forms' of the similarity functions for their small aperture scintillometer studies, however their paths were closer to, or within, the roughness sub-layer. Other large aperture studies in urban environments have used the more common functions (Lagouarde et al. 2006; Zieliński et al. 2012).

Typically, the uncertainty in $z_{0}$ is large as $z_{0}$ can vary spatially, with time of day and stability (Grimmond et al. 1998; Hoedjes et al. 2007; Zilitinkevich et al. 2008), and with shape, density and arrangement of surface structure (Grimmond and Oke 1999). For the study area, the true value is expected to be within the range 0.4 to $1.0 \mathrm{~m}$ based on values in the literature. The impact on the scintillometer estimation of $Q_{H}$ of changing the prescribed values of $z_{0}$ by $\pm 0.2 \mathrm{~m}$ is $\pm 7 \%$ (error bars in Fig. 3a). Although the flux is fairly sensitive to the value of $z_{0}$ used, the overall trends do not change significantly. No adjustment was made to account for seasonal variation in $z_{0}$ (or $z_{d}$ ), though these values may be $10-20 \%$ smaller in winter than in summer (Grimmond et al. 1998). Using a smaller value of $z_{0}$ during leaf-off periods decreases the wintertime fluxes slightly (the error bars in Fig. 3a represent a change in $z_{0}$ of about $\pm 30 \%$ ).

Allowing a $\pm 5 \%$ uncertainty in $z_{e f}( \pm 2.25 \mathrm{~m})$ affects the fluxes by $\pm 3 \%$. This uncertainty in $z_{e f}$ includes measurement accuracy and variation of the effective height with stability as well as accounting for spatial differences in obstacle height (hence $z_{d}$ ) and topography. The large beam height and relatively small displacement height help to keep the sensitivity to $z_{e f}$ (and $z_{d}$ ) small. 


\subsection{Short-term variability}

Direct comparison of 30 min sensible heat fluxes obtained from scintillometry and EC (Fig. 5) indicates reasonably good agreement between the measurement techniques and across the scales with strong correlation $\left(r^{2} \approx 0.87\right)$. The slope of the regression between $Q_{H_{-} L A S}$ and $Q_{H_{-} E C}$ is close to 1 , with a small positive offset, whereas the BLS tends to give lower $Q_{H}$ than EC particularly towards large values of $Q_{H}$. Whilst the linear fit between $Q_{H_{-} L A S}$ and $Q_{H_{-} E C}$ indicates a good match between these data, the BLS data distribution appears more curved at high $Q_{H_{-} E C}$. The source area of the EC mast and BLS are quite different, which may partly explain why the highest EC fluxes are not matched by the BLS. Specifically, the area to the south and south-west of the EC mast has a particularly high proportion of built and impervious surfaces and little vegetation, whilst the BLS source area always includes open green spaces. Thus when the EC footprint is over the least vegetated sector $\left(180-240^{\circ}\right)$, the measured $Q_{H_{-} E C}$ tends to be larger compared to other wind sectors around the flux mast as well as to the scintillometer results. This effect would be amplified when surface water is scarce. During summertime, when the wind is from the south, both $Q_{H_{-} L A S}$ and $Q_{H_{-} B L S}$ are lower than $Q_{H_{-} E C}$ (Fig. 6). For more westerly winds $\left(240-270^{\circ}\right)$ the EC source area contains more vegetation and there is closer agreement between $Q_{H_{-} E C}$ and $Q_{H}$ from the scintillometers.

However, the remaining curvature in Fig. $6 a$, but not seen in Fig. $6 \mathrm{~b}$, most likely indicates saturation affecting the BLS (5.5 km path) but not the LAS on the shorter path. Despite having corrected the scintillometers for saturation (Sect. 2.2), a comparison of the distribution of $C_{T}^{2}$ values from the BLS and LAS suggests that the highest BLS fluxes are still affected: whilst the LAS provides $C_{T}^{2}$ values up to about $0.03 \mathrm{~K}^{2} \mathrm{~m}^{-2 / 3}$, the BLS distribution drops off sharply at around $0.009 \mathrm{~K}^{2} \mathrm{~m}^{-2 / 3}$. Recently, Wood et al. (2013) found an upper $C_{T}^{2}$ threshold of $0.02 \mathrm{~K}^{2} \mathrm{~m}^{-2 / 3}$ for their shorter path length of $4.2 \mathrm{~km}$. Other studies have also suggested that the effects of saturation may still be observed above commonly-used thresholds (Kohsiek et al. 2006).

During night and transition times, the agreement between the datasets is poorer $\left(r^{2}\right.$ decreases to around 0.4 for $K_{\downarrow} \leq 5 \mathrm{~W} \mathrm{~m}^{-2}$ ). This is to be expected for several reasons. Firstly, the limitations in instrument performance are reached when fluxes are small, for both EC and scintillometry. Secondly, the time of stability transition may vary with location, even along the scintillometer paths, so that the three values of $Q_{H}$ obtained for a given time period may not have the same sign. Data points in the second and fourth quadrants indicate when scintillometer and EC derived $Q_{H}$ have opposite signs. The stability may also change more than twice per day which would mean the scintillometer data are processed assuming the wrong stability regime. Thirdly, the corrections for the influence of humidity fluctuations on $C_{T}{ }^{2}$ and $L_{O b}$ are generally larger at these times (when $\beta$ is 
small). The Bowen ratio correction to $C_{T}^{2}$ introduces the larger error of these two approximations; neglecting the buoyancy correction to the Obukhov length (e.g. Green et al. (2001)) is thought to lead to a slight underestimation in $Q_{H}$ of $\approx 0.5 \mathrm{~W} \mathrm{~m}^{-2}$. Finally, near-neutral to stable atmospheric conditions do not always satisfy the assumptions required for the measurement theory (e.g. weak turbulence, non-stationarity, poorer performance of similarity functions). Removing the night time data causes the regression slopes in Fig. 5 to decrease slightly to 0.77 (BLS) and 0.94 (LAS), and the intercepts to increase to $13 \mathrm{~W} \mathrm{~m}^{-2}$ (BLS) and $9 \mathrm{~W} \mathrm{~m}^{-2}$ (LAS). For night time data only, the intercepts are similar in size but of opposite sign. These intercepts are thought to result from the overestimation of small fluxes by the similarity functions. Considering all data together (Fig. 5) the lack of small $Q_{H}$ values from the scintillometers can be identified around zero. Using functions of a conventional form (such as Equations 2 and 3) appears to under represent $Q_{H}$ values close to zero and overestimates $Q_{H}$ in neutral conditions $\left(f_{M O}\right.$ is too small so the $T *$ obtained is too large). Investigation into the scaling of $C_{T}^{2}$ with stability is presented in more detail elsewhere (Ward et al. in preparation a) and Lagouarde et al. (2006) also noted an overestimation (15 $\mathrm{W} \mathrm{m}^{-2}$ ) of small night time $Q_{H}$ values using An88 and DB93 (unstable forms). Although this effect is undesirable, the small size of the fluxes at these times means that absolute errors are small.
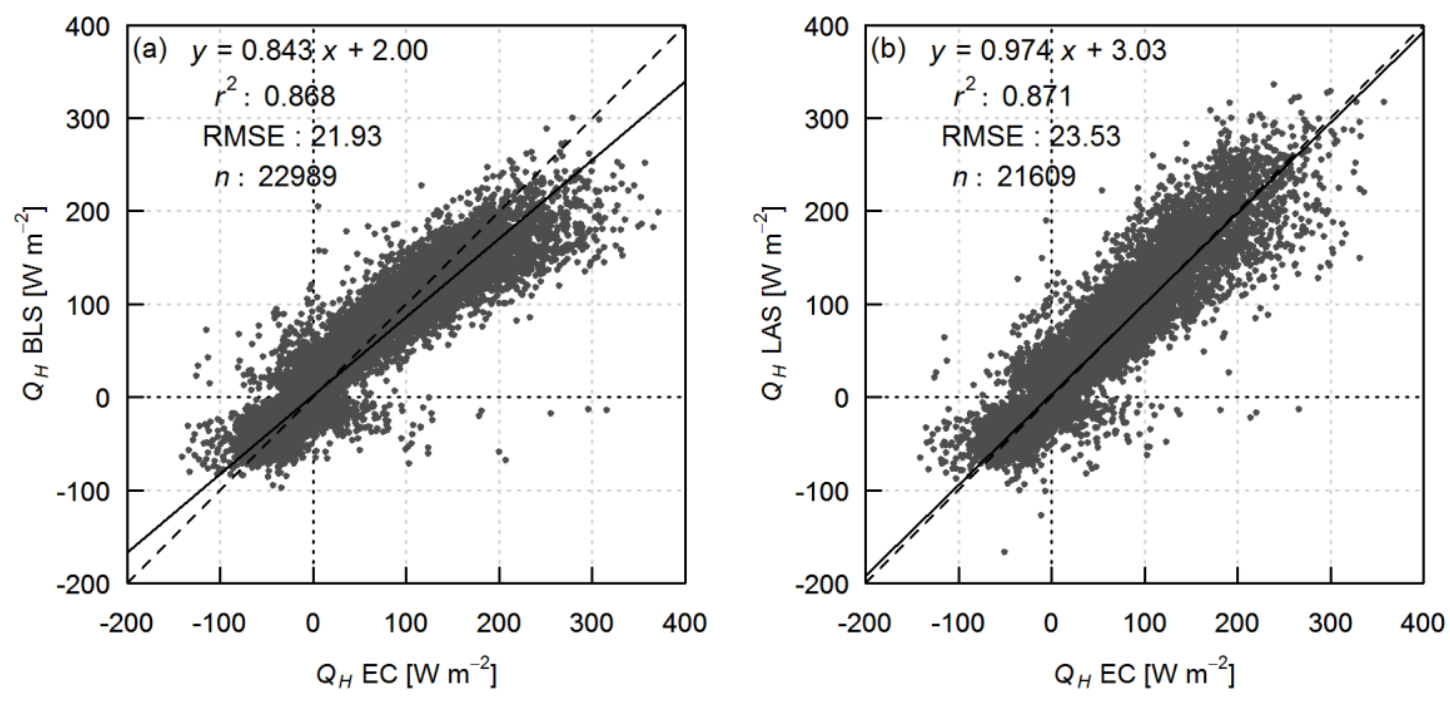

Fig. 5 Comparison of 30 min sensible heat fluxes derived from the scintillometers (BLS, LAS) and eddy covariance (EC) for all 465 available data. 

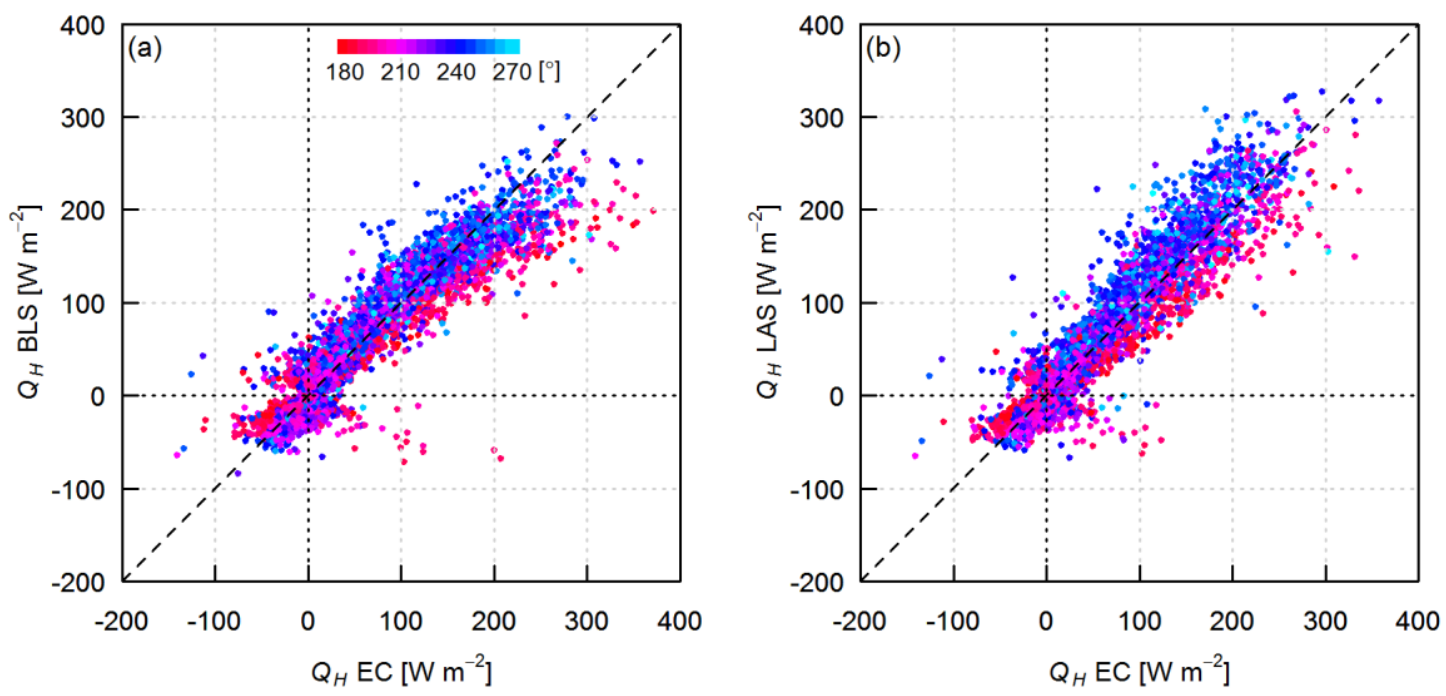

Fig. 6 As for Fig. 5 but for summertime (May-Sep 2011-12) data only and for wind directions 180-270 (colours).

The diurnal course of $Q_{H}$ obtained from the three systems follow each other closely: example days from July 2012 are shown in Fig. 7. No rainfall was observed during these mostly clear-sky days although the influence of cloud cover can be seen on the morning of 22 July and afternoon of 25 July. On 22 July the fluxes respond consistently to changes in the net radiation and the peaks and troughs are closely matched between EC, LAS and BLS observations. Data from MET roof, approximately $3 \mathrm{~km}$ southwards (Fig. 1), closely matches the variation in $Q^{*}$ measured at the EC site. Time-lapse photography reveals fairly uniform, almost full cloud cover at sunrise which clears throughout the morning. On the afternoon of 25 July, however, the situation is quite different. Rapidly changing patchy cloud cover creates spatial variability in the radiation balance components. The responses of the two radiometers are less well correlated (compare $Q^{*}$ and $Q^{*}$ roof in Fig. 7a) and $Q_{H}$ is seen to respond differently across the different measurement scales. Not surprisingly, $Q_{H_{-} E C}$ most closely matches $Q^{*}$ as both are measured at the same location and have more similarly sized and at least partially coincident source areas. In general, the scintillometers yield a more smoothly varying diurnal course than $\mathrm{EC}$, often attributed to the greater spatial averaging by scintillometers (e.g. Lagouarde et al. (2006), Guyot et al. (2009)). The BLS appears to vary more smoothly than the LAS (e.g. 24 July) which is consistent with the size of their source areas.

For clear days, the phase of $Q_{H}$ is lagged relative to $Q^{*}$. At the three scales $Q_{H}$ peaks after $Q^{*}$ and remains positive later into the evening than $Q^{*}$. One component of the urban net heat storage flux is approximated by a heat flux plate installed under the roof covering at $\mathrm{MET}_{\text {roof }}\left(\Delta Q_{S_{-} \text {roof }}\right.$ in Fig. 7a). This flux increases earlier in the day and becomes negative long before $Q^{*}$. In this way, release of 
stored energy enables $Q_{H}$ to remain positive even when $Q^{*}$ is negative (Oke and Cleugh 1987;

490 Lemonsu et al. 2004). Normalising these fluxes by the net radiation clearly demonstrates the opposing hysteresis patterns of $Q_{H}$ compared to $\Delta Q_{S_{\text {rroof }}}\left(\mathrm{Fig}\right.$. 7b). The proportion of $Q^{*}$ directed into sensible heat increases throughout the day whereas the proportion of energy used to heat the surface decreases. Strong hysteresis is evident on clear days but it tends to be less obvious on cloudier days. Similar patterns have been observed at other urban sites at the local-scale (Grimmond and Cleugh 1994; Grimmond and Oke 2002; Grimmond et al. 2004). Here we demonstrate that the phase lag between $Q_{H}$ and $Q^{*}$ is observed right across the urban environment, from the local-scale up to the city-scale. The shift in peak $Q_{H}$ around midday and into early afternoon can also be seen to some extent in the average monthly values (Fig. 4), particularly in spring and early summer 2011.

Other than under conditions of rapidly changing $Q^{*}$, and its associated high spatial variability, the diurnal patterns in $Q_{H}$ derived from EC and the scintillometers match those of $Q^{*}$ measured at the EC site (Fig. 8). On 21, 22 and 27 July 2011 the sudden drop in $Q^{*}$ during the middle of the day is also seen in $Q_{H}$. The day-to-day variation in these two quantities is also very similar. For example $Q^{*}$ and $Q_{H}$ steadily increase to reach over $600 \mathrm{~W} \mathrm{~m}^{-2}$ and 200-300 $\mathrm{W} \mathrm{m}^{-2}$, respectively, on 25 July when peak $Q_{H_{-} B L S}$ is about 2/3 of $Q_{H_{-} L A S}$. Both $Q^{*}$ and $Q_{H}$ are lower during the following few days until 29 July when the net radiation remained very small throughout the day $\left(<100 \mathrm{~W} \mathrm{~m}^{-2}\right)$ and conditions were mostly near-neutral. On this day the agreement in the shape of the diurnal cycle between the scintillometers and EC is poorer, although the fluxes show some agreement in responding to the dip in $Q^{*}$ in the afternoon. Under these near-neutral conditions it is likely that the stability transitions occur more often than twice daily as prescribed by the algorithm used to determine the sign of scintillometric $Q_{H}$. Indeed, $Q_{H_{-} E C}$ is seen to change sign several times during the afternoon and evening. 

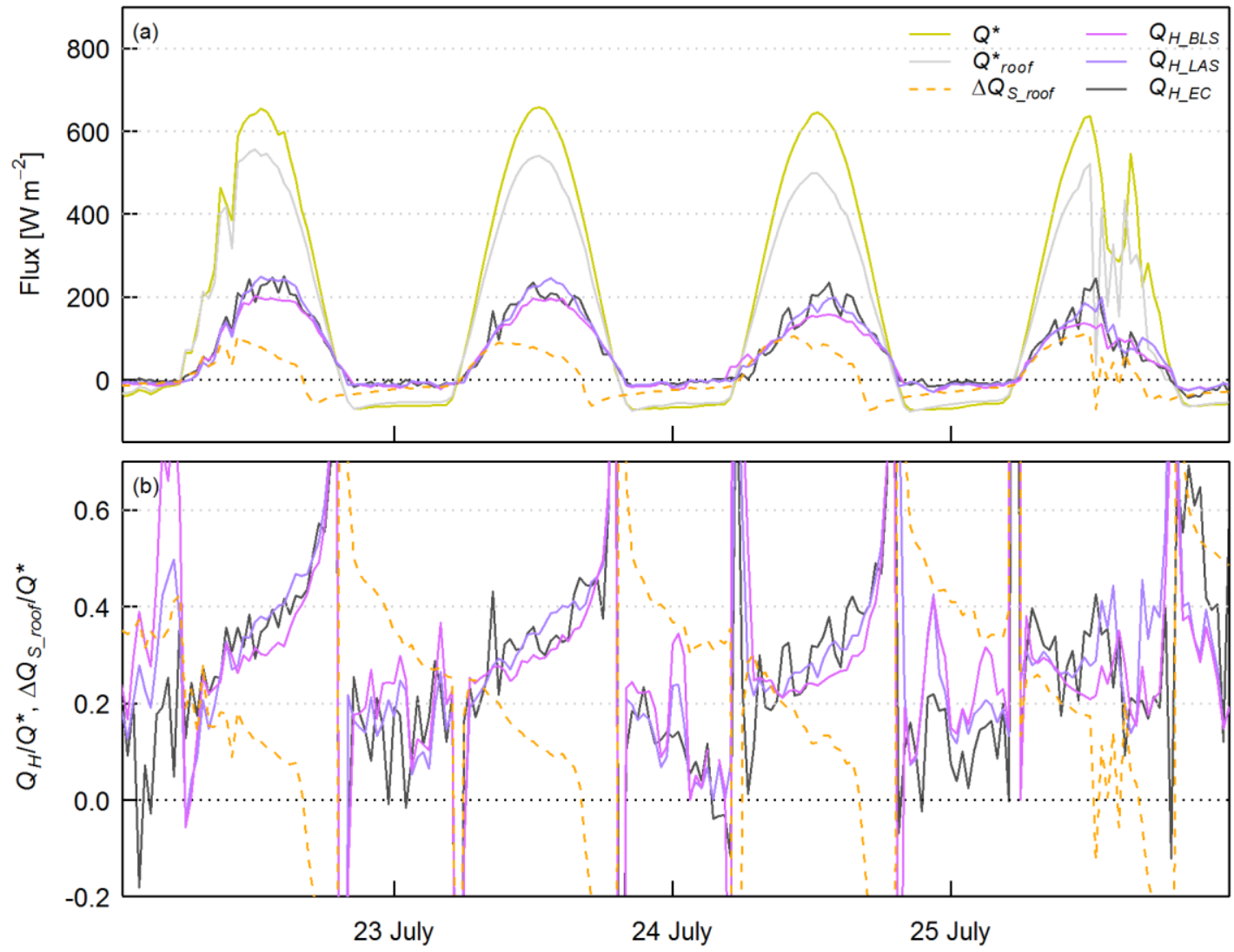

513

514 Fig. 7 Diurnal variation in sensible heat fluxes $\left(Q_{H}\right)$ and net all-wave radiation $\left(Q^{*}\right)$ for four days in July 2012. Data from a 515 heat flux plate installed on a rooftop, representing one component of the storage heat flux $\left(\Delta Q_{S_{-} \text {roof }}\right)$ and a second 516 radiometer located on the rooftop $\left(Q^{*}{ }_{\text {roof }}\right)$ are also shown. In (b) the fluxes have been normalized by the net all-wave 517 radiation measured at the EC site $\left(Q^{*}\right)$. 

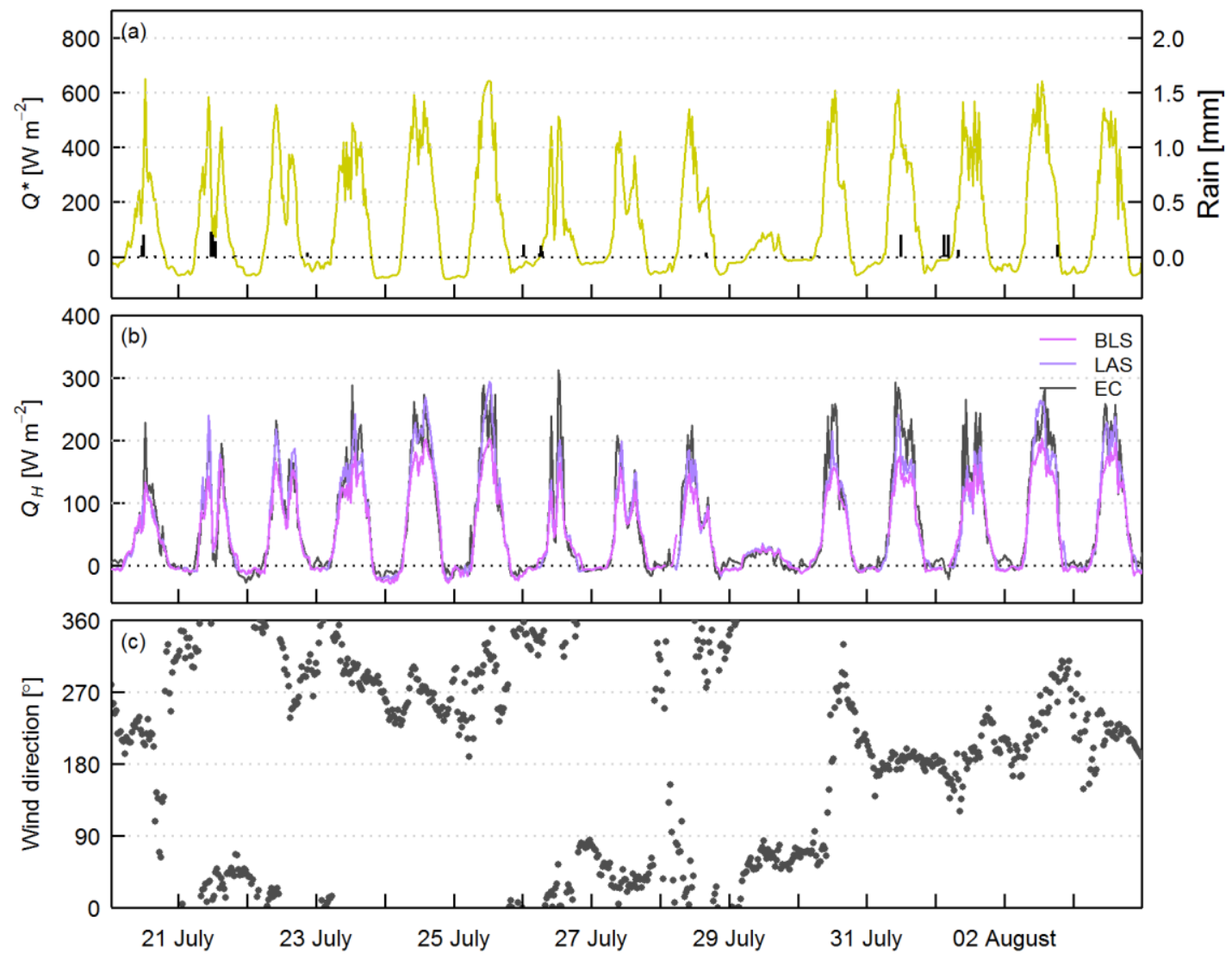

Fig. 8 Sensible heat fluxes from EC and the scintillometers alongside net all-wave radiation from the EC site $(Q *)$, rainfall

The sign of the scintillometer sensible heat flux must be assigned during processing. Here, the stability was assumed to change from stable to unstable at the first minimum in $C_{n}{ }^{2}$ on each day, and from unstable to stable at the second minimum, providing these transitions occurred within the likely time frames for sunrise and sunset. Additionally, the net radiation can be used to check whether the minima identified are likely to indicate stability transitions rather than sudden increases in cloud cover, for example. For each $24 \mathrm{~h}$ period the algorithm always results in some stable and some unstable data and the proportion of each depends on the observed behaviour of $C_{n}{ }^{2}$

530 (effectively on the time between the morning and evening minima). As is evident from the data, this method generally performs well in Swindon, where EC data suggests $Q_{H}$ tends to be positive for some duration around midday and negative at night (Ward et al. 2013a). However, there are some days when the stability transition does not occur and either unstable conditions prevail throughout the night or stable conditions throughout the day. In these cases the sign of the fluxes from the 
scintillometers may be incorrect but these occasions are observed infrequently and the size of the fluxes tends to be small so the likely impact is minimal.

The day-to-day (night-to-night) changes in amplitude are usually captured (e.g. decreasing magnitude of nocturnal $Q_{H}$ 24-27 July 2011 in Fig. 8b) and for some days the evolution of $Q_{H}$ throughout the night is similar (e.g. decreasing 20-21, increasing 25-26 and 26-27 July 2011, Fig. 8b). This clear relation between the scintillometer and EC fluxes gives confidence that the measurement heights are suitable; in particular that the scintillometers are not measuring above the surface layer. In the winter months, occasionally there are periods of a few hours to days when the shallow surface layer means the scintillometer measurements cannot be related to surface fluxes via MOST (Braam et al. 2012). The EC data further supports these findings with very few cases of strongly stable stratification observed $\left(\zeta_{E C}<0.1\right.$ for $89 \%$ of data).

\subsection{Influence of the surface}

Comparing the relative sizes of the fluxes can offer insight into key controls on suburban energy partitioning. Towards the end of the case study in Fig. 8 (30 July-01 August 2011), $Q_{H_{-} E C}$ peaks at larger values than either of the scintillometers, whilst $Q_{H_{-} L A S}$ is generally largest near the beginning of the period (21-25 July). The wind direction (Fig. 8c) provides a partial explanation due to the variation in source areas. For westerly to northerly winds, $Q_{H_{-} L A S}$ tends to be largest. All three fluxes become similar during northerly winds, when there is a greater vegetation fraction within the source area of each instrument. For the scintillometers the footprint will extend to include some of the rural farmland beyond the edge of the suburbs; at the EC site the increased vegetation is due to more gardens to the north of the mast (Ward et al. 2013a).

The period shown in Fig. 9 (21 May - 31 July 2012) coincides with sudden vegetation growth in response to warm, sunny conditions at the end of May, completing the leaf-out period to reach maturity. Vegetation is then fully active throughout June and July. In this period a range of synoptic conditions (cloudy, mixed and clear days), frequent rainfall and a wide distribution of wind directions (although south-westerly was still dominant) occurred.

Footprint calculations for each 30 min period reveal an overall ranking of the vegetation fraction for each instrument that is in accordance with broad expectations given their respective sitings $(E C<$ LAS < BLS). The mean vegetation fractions ( \pm standard deviations) are $44.1( \pm 5.0) \%, 53.9( \pm 2.9) \%$ and $56.9( \pm 4.5) \%$ for EC, LAS and BLS, respectively, for the data shown in Fig. 9. The standard deviation is largest for the EC site, as might be expected (a) given the far smaller size of the source area and (b) the differences in surface cover with wind sector around the mast. The vegetation 
567

568

569

570

571

572

573

574

575

576

577

578

579

580

fraction ranges between $32.6 \%$ and $56.8 \%$ according to the EC footprint estimation for this period. The LAS source area characteristics are much less variable (minimum $47.7 \%$, maximum $60.2 \%$ ). The retail park to the west of the path (Fig. 1) constitutes a small proportion of the total source area and for westerly wind directions there is only a small increase in the built and impervious fractions. Despite having the largest area, the BLS footprint shows appreciable variability $(48.3 \%-65.7 \%)$, mostly associated with southerly or northerly winds when the town centre and nearby industrial areas (Fig. 1) or rural surroundings are included in the footprint. For small changes in wind direction the BLS source area composition hardly changes, whereas the EC source area composition can vary considerably (particularly for the $180-270^{\circ}$ sector). In addition to the directional aspect of the surface heterogeneity, the total area included in the scintillometer footprint is smaller when the wind direction is parallel, as opposed to perpendicular, to the scintillometer path (Meijninger et al. 2002b). In this case, the spatial integration occurs over a smaller area so the footprint composition, and observed fluxes, may be expected to be more variable.

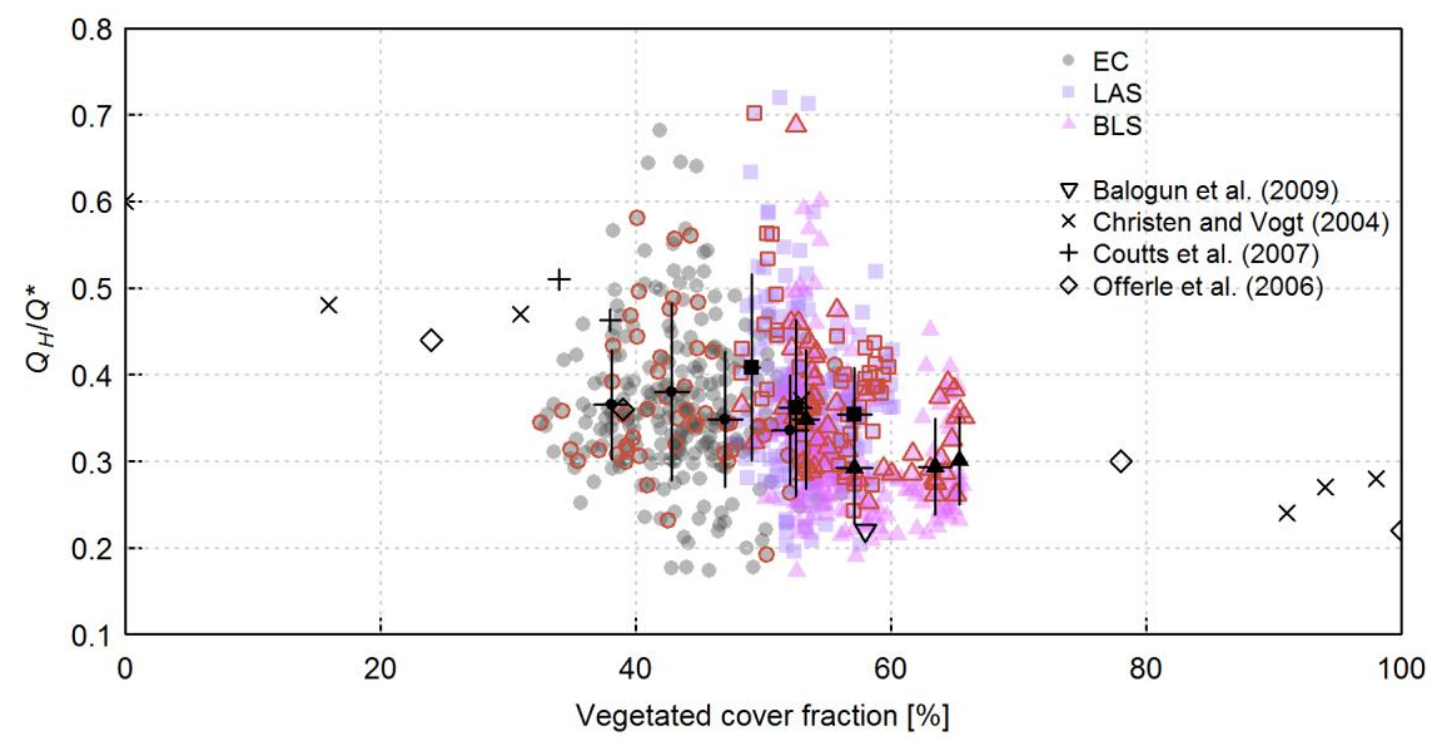

581

Fig. 9 Ratio of observed sensible heat flux to net all-wave radiation versus the proportion of vegetation within the flux footprint of the EC station, LAS and BLS in Swindon. Points are 30 min values around midday (1100-1500 UTC) for the period 21 May - 31 July 2012. Data are excluded for times during and $\leq 2 \mathrm{~h}$ after rainfall and when $K_{\downarrow} \leq 200 \mathrm{~W} \mathrm{~m}^{-2}$. Black symbols with error bars represent the mean \pm standard deviation of the respective observed values binned in $5 \%$ intervals of the vegetated cover fraction (bins with > 10 data points are plotted). Those data collected more than 2 days since rainfall are outlined in red. Average summertime values from various sites in the literature are shown for comparison (see references for details). 
The ratio of $Q_{H}$ to $Q^{*}$ decreases as the proportion of vegetation within each instrument's source area increases (Fig. 9). Normalising the turbulent fluxes by an indicator of the energy available

592 largely removes the otherwise often dominant dependence on insolation. Additionally, to moderate 593 the influence of the diurnal hysteresis pattern (Fig. 7), only data around midday (1100-1500 UTC) 594 have been included in Fig. 9. The observed relation between vegetation cover and partitioning of energy into $Q_{H}$ is in agreement with other published studies, including summertime data from Kansas City (Balogun et al. 2009), seven sites in Basel (Christen and Vogt 2004), two sites (high and medium density) in Melbourne (Coutts et al. 2007) and four sites in Łódź (Offerle et al. 2006). Use of the scintillometers in Swindon enables this comparison to be extended to larger scales.

Relations between land cover and energy partitioning have mostly been developed for summer months, when the majority of field campaigns have taken place and do not account for differences in surface or synoptic conditions. Whilst there is generally good agreement between summertime datasets across a range of sites, those studies extending to winter demonstrate very different behaviour of $Q_{H} / Q^{*}$. In dense urban areas, the anthropogenic heat flux and much larger storage flux can sustain a positive sensible heat flux all year round (Goldbach and Kuttler 2013; Kotthaus and Grimmond in press-a). In these locations, building density may be a more appropriate variable to use than vegetation fraction and the effect of the anthropogenic heat flux can result in $Q_{H}$ that is significantly greater than $Q^{*}$. The few campaigns spanning multiple seasons indicate temporal evolution of daytime $Q_{H} / Q^{*}$, e.g. between about 0.30 (winter) and 0.55 (summer) in Melbourne (Coutts et al. 2007), and between 0.29 (December) and 0.49 (July) in Tokyo (Moriwaki and Kanda 2004). The data presented here reveal daytime $Q_{H} / Q^{*}$ peaks in spring between 0.4 and 0.5 and drops to about 0.2 in winter for Swindon. These seasonal changes incorporate multiple effects. The anthropogenic influences already mentioned, vegetative activity and the amount of incoming radiation are major factors, but do not account for inter-annual variability in meteorological conditions or rainfall. In February 2012 the limited moisture availability likely contributed to an atypically high $Q_{H} / Q^{*}$ of around 0.4 .

At shorter time scales, the meteorological conditions and local stability both have an influence. Reduced availability of moisture constrains the latent heat flux and allows the sensible heat to rise. Following rainfall, the surface dries out and the ratio $Q_{H} / Q^{*}$ tends to increase (outlined points in Fig. 9 represent data collected following more than 2 days without rainfall). Inter-annual variations in rainfall can lead to differences in the size of the fluxes from year to year that cannot only be attributed to variations in $Q^{*}$ (Fig. 3). Although normalising by $Q^{*}$ removes much of the dependence 
on the radiative energy, whether conditions are clear or cloudy can affect the response of the surface. Some studies have stratified results by cloud cover conditions (Grimmond and Oke 1995; Balogun et al. 2009) although the effect on $Q_{H} / Q^{*}$ is small. In Fig. 9, data are excluded for $K_{\downarrow} \leq 200$

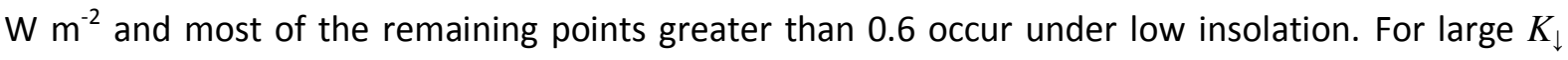
values the scatter is further reduced; this likely to be a result of differing conditions within the instruments' source areas under variable cloud cover. The sensible heat flux is dependent on the amount of energy stored and released, which itself depends on the season (Offerle et al. 2005), surface wetness (Kawai and Kanda 2010) and cloud cover (Grimmond and Oke 1995). The ability of the surface to store or dissipate heat depends primarily on the physical properties of the constituent materials, but may also be affected by changes in surface conditions, for example a wet surface may have a lower albedo than when dry (e.g. in Cairo (Frey et al. 2011)) and soil moisture affects its conductivity. Different materials respond differently to direct and diffuse radiation (Kotthaus and Grimmond in press-b). In combination with surface morphology and changing solar elevation with latitude and time of year, this determines the impact of shadowing. To account for shading patterns in energy flux parameterization schemes Loridan and Grimmond (2012) propose an 'active' built index. The latent heat flux also depends on these, and other, factors. To further develop understanding of such processes and interactions it will be necessary to focus more attention on the interdependencies between energy fluxes and how these are affected by surface conditions in urban areas.

Finally, although the Bowen ratio correction has not been applied to the data here, the biggest impact of the correction would be at small $\beta$. For $\beta=0.5$, scintillometric $Q_{H}$ is overestimated by $9 \%$ which would result in mean $Q_{H} / Q^{*}$ being overestimated by 0.04 . Implementing the $\beta$ correction would act to further decrease $Q_{H} / Q^{*}$ with vegetation fraction. As $\beta$ itself has been shown to depend on the vegetation fraction, smaller $\beta$ at larger vegetation fraction again acts to amplify rather than reduce the trend.

\section{Conclusions}

This work demonstrates the applicability of large aperture scintillometry for making spatially integrated observations over urban areas. With selection of a suitable path, adequately sited auxiliary meteorological measurements and knowledge of the land surface, sensible heat flux estimates are obtained that are representative of several neighbourhoods or across the settlement. Whilst EC measurements are representative of the local-scale $\left(0.5 \mathrm{~km}^{2}\right)$, the scintillometer data in this study have much larger source areas: 3.0 and $7.5 \mathrm{~km}^{2}$ (95\% contribution) for the LAS and BLS, respectively. 
Remarkable temporal agreement is observed across the three different areal extents for both short-term variability (e.g. the response to radiation patterns over a few hours to days) and seasonal trends. Differences in magnitudes of the fluxes between sites are attributed primarily to the role of vegetation and reveal the influence of anthropogenic materials on surface-atmosphere interactions. Empirical relations between land cover and fluxes often underpin urban energy models and are valuable for gauging the likely partitioning of energy, and hence the environmental conditions (including thermal comfort and moisture availability), in cities where measurements have not been made.

Comparison of the EC dataset with large-area fluxes at the city-scale provides some context to the results and confirms that the EC site selection was appropriate. The scintillometer fluxes tend to be smoother as a result of the greater spatial averaging. The large-scale flux measurements are also much less sensitive to source area variability, for example due to changing wind direction over heterogeneous surfaces. As they encompass a larger proportion of the study area, these large-area fluxes are more representative and suffer less from sampling bias, whereas EC measurements are easily influenced by spatially variable land cover or surface characteristics around the mast. The effect can be decreased by measuring at a greater height, but in general the land cover must be carefully examined for each wind sector before drawing conclusions on the representativeness of data from a single EC site.

For many purposes we are interested in fluxes at large scales, whether the application is input data for, or evaluation of, land-surface models or numerical weather prediction, assessment of satellite remote sensing products or representative observational datasets to characterize a particular environment. Scintillometry offers a promising way forward, but there are still limitations. A major source of uncertainty arises from the MOST functions. This is an area that would benefit from further attention for all land cover types and has implications beyond improving the accuracy of fluxes from scintillometry. Single-wavelength scintillometry may be best suited to urban areas with little vegetation as the higher the Bowen ratio the smaller the error due to neglecting the $\beta$ correction (Moene 2003). Given the potential for saturation, particularly if the sensible heat flux is large, it is recommended that an extra-large aperture scintillometer is considered for long paths (e.g. $>4 \mathrm{~km}$, for paths of similar height and fluxes of similar magnitude). Future work will likely focus on the development of the scintillometry technique and the application for routine monitoring at largescales, e.g. Kleissl et al. (2009a). Such observational networks would offer valuable data for assimilation into models that assess e.g. air quality or heat stress, both highly relevant to human health and well-being. 


\section{Acknowledgements}

689

690

691

692

693

694

695

696

697

698

699

700

701

702

703

704

705

706

707

708

709

710

711

712

713

714

715

716

717

718

719

720

721

722

723

724

725

726

727

728

729

We gratefully acknowledge the support of the following CEH staff: Alan Warwick and Cyril Barrett for design and construction of the scintillometer mountings, Geoff Wicks for assistance with the electronics and Dave McNeil for helping to build the rooftop weather station. This work would not have been possible without the generous co-operation of several people in Swindon who very kindly gave permission for equipment to be installed on their property. We also wish to thank the Science and Technology Facilities Council staff at Chilbolton Observatory for use of their test range for the scintillometer comparison. This work was funded by the Natural Environment Research Council, UK.

\section{References}

Andreas EL (1988) Estimating $\mathrm{C}_{\mathrm{n}}{ }^{2}$ over snow and sea ice from meteorological data. J Opt Soc Am 5: 481-495.

Andreas EL (1989) Two-wavelength method of measuring path-averaged turbulent surface heat fluxes. J Atmos Ocean Technol 6: 280-292.

Balogun A, Adegoke J, Vezhapparambu S, Mauder M, McFadden J and Gallo K (2009) Surface energy balance measurements above an exurban residential neighbourhood of Kansas City, Missouri. Boundary-Layer Meteorol 133: 299-321. doi: 10.1007/s10546-009-9421-3

Bergeron $O$ and Strachan IB (2010) Wintertime radiation and energy budget along an urbanization gradient in Montreal, Canada. Int J Climatol 32: 137-152. doi: 10.1002/joc.2246

Beyrich F, Bange J, Hartogensis O, Raasch S, Braam M, van Dinther D, Gräf D, van Kesteren B, van den Kroonenberg A, Maronga B, Martin S and Moene A (2012) Towards a Validation of Scintillometer Measurements: The LITFASS-2009 Experiment. Boundary-Layer Meteorol 144: 83-112. doi: 10.1007/s10546-012-9715-8

Beyrich F, De Bruin HAR, Meijninger WML, Schipper JW and Lohse H (2002) Results from one-year continuous operation of a large aperture scintillometer over a heterogeneous land surface. Boundary-Layer Meteorol 105: 85-97.

Braam M, Bosveld F and Moene A (2012) On Monin-Obukhov Scaling in and Above the Atmospheric Surface Layer: The Complexities of Elevated Scintillometer Measurements. Boundary-Layer Meteorol 144: 157-177. doi: 10.1007/s10546-012-9716-7

Chehbouni A, Watts C, Kerr YH, Dedieu G, Rodriguez JC, Santiago F, Cayrol P, Boulet G and Goodrich DC (2000a) Methods to aggregate turbulent fluxes over heterogeneous surfaces: application to SALSA data set in Mexico. Agric For Meteorol 105: 133-144.

Chehbouni A, Watts C, Lagouarde JP, Kerr YH, Rodriguez JC, Bonnefond JM, Santiago F, Dedieu G, Goodrich DC and Unkrich C (2000b) Estimation of heat and momentum fluxes over complex terrain using a large aperture scintillometer. Agric For Meteorol 105: 215-226.

Cheinet S, Beljaars A, Weiss-Wrana K and Hurtaud Y (2011) The Use of Weather Forecasts to Characterise Near-Surface Optical Turbulence. Boundary-Layer Meteorol 138: 453-473. doi: 10.1007/s10546-010-9567-z

Christen A and Vogt R (2004) Energy and radiation balance of a central European city. Int J Climatol 24: 1395-1421. doi: 10.1002/joc.1074

Clifford SF, Ochs GR and Lawrence RS (1974) Saturation of optical scintillation by strong turbulence. J Opt Soc Am 64: 148-154. 
Coutts AM, Beringer J and Tapper NJ (2007) Impact of increasing urban density on local climate: Spatial and temporal variations in the surface energy balance in Melbourne, Australia. J Appl Meteorol Climatol 46: 477-493. doi: 10.1175/jam2462.1

De Bruin HAR, Kohsiek W and Van den Hurk BJJM (1993) A verification of some methods to determine the fluxes of momentum, sensible heat, and water-vapour using standarddeviation and structure parameter of scalar meteorological quantities. Boundary-Layer Meteorol 63: 231-257.

Detto M, Montaldo N, Albertson JD, Mancini M and Katul G (2006) Soil moisture and vegetation controls on evapotranspiration in a heterogeneous Mediterranean ecosystem on Sardinia, Italy. Water Resour Res 42: 16. doi: 10.1029/2005wr004693

Evans JG (2009) Long-Path Scintillometry over Complex Terrain to Determine Areal-Averaged Sensible and Latent Heat Fluxes. Soil Science Department, The University of Reading, PhD, $181 \mathrm{pp}$

Evans JG, McNeil DD, Finch JW, Murray T, Harding RJ, Ward HC and Verhoef A (2012) Determination of turbulent heat fluxes using a large aperture scintillometer over undulating mixed agricultural terrain. Agric For Meteorol 166-167: 221-233.

Ezzahar J, Chehbouni A and Hoedjes JCB (2007) On the application of scintillometry over heterogeneous grids. J Hydrol 334: 493-501. doi: 10.1016/j.jhydrol.2006.10.027

Frey CM, Parlow E, Vogt R, Harhash M and Abdel Wahab MM (2011) Flux measurements in Cairo. Part 1: in situ measurements and their applicability for comparison with satellite data. Int J Climatol 31: 218-231. doi: 10.1002/joc.2140

Garratt JR (1978) Transfer characteristics for a heterogeneous surface of large aerodynamic roughness. Q J R Meteorol Soc 104: 491-502. doi: 10.1002/qj.49710444019

Garratt JR (1992) The Atmospheric Boundary Layer, Cambridge University Press, 316 pp

Goldbach A and Kuttler W (2013) Quantification of turbulent heat fluxes for adaptation strategies within urban planning. Int J Climatol 33: 143-159. doi: 10.1002/joc.3437

Gouvea ML and Grimmond CSB (2010) Spatially integrated measurements of sensible heat flux using scintillometry. Ninth Symposium on the Urban Environment, Keystone, Colorado, 2nd-6th August 2010

Green AE, Astill MS, McAneney KJ and Nieveen JP (2001) Path-averaged surface fluxes determined from infrared and microwave scintillometers. Agric For Meteorol 109: 233-247.

Grimmond CSB and Cleugh HA (1994) A Simple Method to Determine Obukhov Lengths for Suburban Areas. J Appl Meteorol 33: 435-440.

Grimmond CSB, King TS, Roth M and Oke TR (1998) Aerodynamic roughness of urban areas derived from wind observations. Boundary-Layer Meteorol 89: 1-24.

Grimmond CSB and Oke TR (1995) Comparison of Heat Fluxes from Summertime Observations in the Suburbs of Four North American Cities. J Appl Meteorol 34: 873-889. doi: 10.1175/15200450

Grimmond CSB and Oke TR (1999) Aerodynamic properties of urban areas derived from analysis of surface form. J Appl Meteorol 38: 1262-1292.

Grimmond CSB and Oke TR (2002) Turbulent heat fluxes in urban areas: Observations and a localscale urban meteorological parameterization scheme (LUMPS). J Appl Meteorol 41: 792-810.

Grimmond CSB, Salmond JA, Oke TR, Offerle B and Lemonsu A (2004) Flux and turbulence measurements at a densely built-up site in Marseille: Heat, mass (water and carbon dioxide), and momentum. J Geophys Res (Atmos) 109: D24101. doi: D2410110.1029/2004jd004936

Grimmond CSB, Souch C and Hubble MD (1996) Influence of tree cover on summertime surface energy balance fluxes, San Gabriel Valley, Los Angeles. Climate Res 06: 45-57. doi: 10.3354/cr006045

Guyot A, Cohard J-M, Anquetin S, Galle S and Lloyd CR (2009) Combined analysis of energy and water balances to estimate latent heat flux of a Sudanian small catchment. J Hydrol 375: 227-240. 
Hartogensis OK, Watts CJ, Rodriguez JC and De Bruin HAR (2003) Derivation of an effective height for scintillometers: La Poza experiment in Northwest Mexico. J Hydrometerol 4: 915-928.

Hill RJ, Bohlander RA, Clifford SF, McMillan RW, Priestly JT and Schoenfeld WP (1988) Turbulenceinduced millimeter-wave scintillation compared with micrometeorological measurements. IEEE Trans Geosci Remote Sens 26: 330-342.

Hill RJ, Clifford SF and Lawrence RS (1980) Refractive-index and absorption fluctuations in the infrared caused by temperature, humidity, and pressure fluctuations. J Opt Soc Am 70: 11921205.

Hill RJ, Ochs GR and Wilson JJ (1992) Measuring surface-layer fluxes of heat and momentum using optical scintillation. Boundary-Layer Meteorol 58: 391-408. doi: 10.1007/bf00120239

Hiller RV, McFadden JP and Kljun N (2011) Interpreting CO2 Fluxes Over a Suburban Lawn: The Influence of Traffic Emissions. Boundary-Layer Meteorol 138: 215-230. doi: 10.1007/s10546010-9558-0

Hoedjes JCB, Chehbouni A, Ezzahar J, Escadafal R and De Bruin HAR (2007) Comparison of large aperture scintillometer and eddy covariance measurements: Can thermal infrared data be used to capture footprint-induced differences? J Hydrometerol 8: 144-159. doi: 10.1175/jhm561.1

Hoedjes JCB, Zuurbier RM and Watts CJ (2002) Large aperture scintillometer used over a homogeneous irrigated area, partly affected by regional advection. Boundary-Layer Meteorol 105: 99-117.

Hsieh Cl, Katul G and Chi T (2000) An approximate analytical model for footprint estimation of scalar fluxes in thermally stratified atmospheric flows. Adv Water Resour 23: 765-772.

Järvi L, Grimmond CSB and Christen A (2011) The Surface Urban Energy and Water Balance Scheme (SUEWS): Evaluation in Los Angeles and Vancouver. J Hydrol 411: 219-237.

Järvi L, Nordbo A, Junninen H, Riikonen A, Moilanen J, Nikinmaa E and Vesala T (2012) Seasonal and annual variation of carbon dioxide surface fluxes in Helsinki, Finland, in 2006-2010. Atmos Chem Phys 12: 8475-8489. doi: 10.5194/acp-12-8475-2012

Järvi L, Rannik U, Mammarella I, Sogachev A, Aalto PP, Keronen P, Siivola E, Kulmala M and Vesala T (2009) Annual particle flux observations over a heterogeneous urban area. Atmos Chem Phys 9: 7847-7856.

Kanda M, Moriwaki R, Roth M and Oke T (2002) Area-averaged sensible heat flux and a new method to determine zero-plane displacement length over an urban surface using scintillometry. Boundary-Layer Meteorol 105: 177-193.

Kawai T and Kanda M (2010) Urban Energy Balance Obtained from the Comprehensive Outdoor Scale Model Experiment. Part I: Basic Features of the Surface Energy Balance. J Appl Meteorol Climatol 49: 1341-1359. doi: 10.1175/2010jamc1992.1

Keogh S, Mills G and Fealy R (2012) The energy budget of the urban surface: two locations in Dublin. Irish Geography 45: 1-23. doi: 10.1080/00750778.2012.689182

Kleissl J, Gomez J, Hong SH, Hendrickx JMH, Rahn T and Defoor WL (2008) Large aperture scintillometer intercomparison study. Boundary-Layer Meteorol 128: 133-150. doi: 10.1007/s10546-008-9274-1

Kleissl J, Hartogensis O and Gomez J (2010) Test of Scintillometer Saturation Correction Methods Using Field Experimental Data. Boundary-Layer Meteorol 137: 493-507. doi: 10.1007/s10546-010-9540-x

Kleissl J, Hong SH and Hendrickx JMH (2009a) New Mexico scintillometer network supporting remote sensing and hydrologic and meteorological models. Bull Am Meteorol Soc 90: 207-218. doi: 10.1175/2008bams2480.1

Kleissl J, Watts CJ, Rodriguez JC, Naif S and Vivoni ER (2009b) Scintillometer Intercomparison StudyContinued. Boundary-Layer Meteorol 130: 437-443. doi: 10.1007/s10546-009-9352-z

Kohsiek W and Herben MHAJ (1983) Evaporation derived from optical and radio-wave scintillation. Appl Opt 22: 2566-2570. 
Kohsiek W, Meijninger WML, De Bruin HAR and Beyrich F (2006) Saturation of the Large Aperture Scintillometer. Boundary-Layer Meteorol 121: 111-126. doi: 10.1007/s10546-005-9031-7

Kotthaus S and Grimmond CSB (in press-a) Energy exchange in a dense urban environment - Part I: temporal variability of long-term observations in central London. Urban Climate. doi: 10.1016/j.uclim.2013.10.002

Kotthaus S and Grimmond CSB (in press-b) Energy exchange in a dense urban environment - Part II: impact of spatial heterogeneity of the surface. Urban Climate. doi: 10.1016/j.uclim.2013.10.001

Lagouarde JP, Irvine M, Bonnefond JM, Grimmond CSB, Long N, Oke TR, Salmond JA and Offerle B (2006) Monitoring the sensible heat flux over urban areas using large aperture scintillometry: Case study of Marseille city during the ESCOMPTE experiment. BoundaryLayer Meteorol 118: 449-476. doi: 10.1007/s10546-005-9001-0

Lemonsu A, Grimmond CSB and Masson V (2004) Modeling the surface energy balance of the core of an old Mediterranean city: Marseille. J Appl Meteorol 43: 312-327.

Liu SM, Xu ZW, Zhu ZL, Jia ZZ and Zhu MJ (2013) Measurements of evapotranspiration from eddycovariance systems and large aperture scintillometers in the Hai River Basin, China.J Hydrol 487: 24-38. doi: http://dx.doi.org/10.1016/j.jhydrol.2013.02.025

Loridan T and Grimmond CSB (2012) Characterization of Energy Flux Partitioning in Urban Environments: Links with Surface Seasonal Properties. J Appl Meteorol Climatol 51: 219-241. doi: 10.1175/jamc-d-11-038.1

Maronga B, Moene AF, Dinther D, Raasch S, Bosveld FC and Gioli B (2013) Derivation of Structure Parameters of Temperature and Humidity in the Convective Boundary Layer from LargeEddy Simulations and Implications for the Interpretation of Scintillometer Observations. Boundary-Layer Meteorol 148: 1-30. doi: 10.1007/s10546-013-9801-6

Maronga B and Raasch S (2013) Large-Eddy Simulations of Surface Heterogeneity Effects on the Convective Boundary Layer During the LITFASS-2003 Experiment. Boundary-Layer Meteorol 146: 17-44. doi: 10.1007/s10546-012-9748-z

Meijninger WML, Beyrich F, Lüdi A, Kohsiek W and De Bruin HAR (2006) Scintillometer-based turbulent fluxes of sensible and latent heat over a heterogeneous land surface - A contribution to LITFASS-2003. Boundary-Layer Meteorol 121: 89-110. doi: 10.1007/s10546005-9022-8

Meijninger WML and De Bruin HAR (2000) The sensible heat fluxes over irrigated areas in western Turkey determined with a large aperture scintillometer. J Hydrol 229: 42-49.

Meijninger WML, Green AE, Hartogensis OK, Kohsiek W, Hoedjes JCB, Zuurbier RM and De Bruin HAR (2002a) Determination of area-averaged water vapour fluxes with large aperture and radio wave scintillometers over a heterogeneous surface - Flevoland field experiment. BoundaryLayer Meteorol 105: 63-83.

Meijninger WML, Hartogensis OK, Kohsiek W, Hoedjes JCB, Zuurbier RM and De Bruin HAR (2002b) Determination of area-averaged sensible heat fluxes with a large aperture scintillometer over a heterogeneous surface - Flevoland field experiment. Boundary-Layer Meteorol 105: 37-62.

Mestayer P, Bagga I, Calmet I, Fontanilles G, Gaudin D, Lee JH, Piquet T, Rosant J-M, Chancibault K, Lebouc L, Letellier L, Mosini M-L, Rodriguez F, Rouaud J-M, Sabre M, Tétard Y, Brut A, Selves J-L, Solignac P-A, Brunet $Y$, Dayau S, Irvine M, Lagouarde J-P, Kassouk Z, Launeau P, Connan $O$, Defenouillère $P$, Goriaux M, Hébert D, Letellier B, Mario D, Najjar G, Nerry F, Quentin C, Biron R, Cohard J-M, Galvez J and Klein P (2011) The FluxSAP 2010 hydroclimatological experimental campaign over an heterogeneous urban area. 11th EMS Annual Meeting, Berlin, Germany, 12th-16th September 2011

Moene AF (2003) Effects of water vapour on the structure parameter of the refractive index for near-infrared radiation. Boundary-Layer Meteorol 107: 635-653. 
Moriwaki R and Kanda M (2004) Seasonal and diurnal fluxes of radiation, heat, water vapor, and carbon dioxide over a suburban area. J Appl Meteorol 43: 1700-1710.

Mustchin J, Pauscher L, Ward HC, Kotthaus S, Gouvea M, Morrison W and Grimmond CSB (2013) Comparison of Three Large Aperture Scintillometer Models Over London. Tübingen Atmospheric Physics Symposium "Scintillometers and Applications", Tübingen, Germany, 7th-9th October 2013

Nordbo A, Järvi L, Haapanala S, Moilanen J and Vesala T (2013) Intra-City Variation in Urban Morphology and Turbulence Structure in Helsinki, Finland. Boundary-Layer Meteorol 146: 469-496. doi: 10.1007/s10546-012-9773-y

Offerle B, Grimmond CSB and Fortuniak K (2005) Heat storage and anthropogenic heat flux in relation to the energy balance of a central European city centre. Int J Climatol 25: 14051419. doi: $10.1002 /$ koc. 1198

Offerle B, Grimmond CSB, Fortuniak K and Pawlak W (2006) Intraurban differences of surface energy fluxes in a central European city. J Appl Meteorol Climatol 45: 125-136.

Oke TR and Cleugh HA (1987) Urban heat storage derived as energy balance residuals. BoundaryLayer Meteorol 39: 233-245. doi: 10.1007/bf00116120

Pasquill F (1974) Atmospheric Diffusion, Wiley, 429 pp

Pauscher L (2010) Scintillometer Measurements above the Urban Area of London. Department of Micrometeorology, University of Bayreuth, Diploma, $104 \mathrm{pp}$

Roberts SM, Oke TR, Grimmond CSB and Voogt JA (2006) Comparison of Four Methods to Estimate Urban Heat Storage. J Appl Meteorol Climatol 45: 1766-1781. doi: 10.1175/jam2432.1

Roth M, Salmond JA and Satyanarayana ANV (2006) Methodological considerations regarding the measurement of turbulent fluxes in the urban roughness sublayer: The role of scintillometery. Boundary-Layer Meteorol 121: 351-375. doi: 10.1007/s10546-006-9074-4

Samain B, Defloor W and Pauwels VRN (2012) Continuous Time Series of Catchment-Averaged Sensible Heat Flux from a Large Aperture Scintillometer: Efficient Estimation of Stability Conditions and Importance of Fluxes under Stable Conditions. J Hydrometerol 13: 423-442. doi: 10.1175/jhm-d-11-030.1

Samain B, Ferket BVA, Defloor W and Pauwels VRN (2011a) Estimation of catchment averaged sensible heat fluxes using a large aperture scintillometer. Water Resour Res 47: W05536. doi: 10.1029/2009wr009032

Samain B, Simons GWH, Voogt MP, Defloor W, Bink N-J and Pauwels VRN (2011b) Consistency between hydrological model, large aperture scintillometer and remote sensing based evapotranspiration estimates for a heterogeneous catchment. Hydrol Earth Syst Sci 8: 10863-10894. doi: 10.5194/hessd-8-10863-2011

Schmid HP (1994) Source areas for scalars and scalar fluxes. Boundary-Layer Meteorol 67: 293-318. doi: $10.1007 / \mathrm{bf00713146}$

Schmid HP, Cleugh HA, Grimmond CSB and Oke TR (1991) Spatial variability of energy fluxes in suburban terrain. Boundary-Layer Meteorol 54: 249-276. doi: 10.1007/bf00183956

Steeneveld GJ, Tolk LF, Moene AF, Hartogensis OK, Peters W and Holtslag AAM (2011) Confronting the WRF and RAMS mesoscale models with innovative observations in the Netherlands: Evaluating the boundary layer heat budget. J Geophys Res (Atmos) 116: D23114. doi: 10.1029/2011jd016303

Stull RB (1988) An Introduction to Boundary Layer Meteorology, Kluwer Academic Publishers, 666 pp

Thiermann V and Grassl H (1992) The measurement of turbulent surface-layer fluxes by use of bichromatic scintillation. Boundary-Layer Meteorol 58: 367-389.

Van Kesteren B and Hartogensis O (2011) Analysis of the Systematic Errors Found in the Kipp \& Zonen Large-Aperture Scintillometer. Boundary-Layer Meteorol 138: 493-509. doi: 10.1007/s10546-010-9564-2 
Vesala T, Järvi L, Launiainen S, Sogachev A, Rannik Ü, Mammarella I, Siivola E, Keronen P, Rinne J, Riikonen ANU and Nikinmaa E (2008) Surface-atmosphere interactions over complex urban terrain in Helsinki, Finland. Tellus B 60: 188-199. doi: 10.1111/j.1600-0889.2007.00312.x

Ward HC, Evans JG and Grimmond CSB (2013a) Multi-season eddy covariance observations of energy, water and carbon fluxes over a suburban area in Swindon, UK. Atmos Chem Phys 13: 4645-4666. doi: 10.5194/acp-13-4645-2013

Ward HC, Evans JG, Hartogensis OK, Moene AF, De Bruin HAR and Grimmond CSB (2013b) A critical revision of the estimation of the latent heat flux from two-wavelength scintillometry. Q J R Meteorol Soc 139: 1912-1922. doi: 10.1002/qj.2076

Weber S and Kordowski K (2010) Comparison of atmospheric turbulence characteristics and turbulent fluxes from two urban sites in Essen, Germany. Theor Appl Climatol 102: 61-74. doi: 10.1007/s00704-009-0240-8

Wesely ML (1976) Combined effect of temperature and humidity fluctuations on refractive-index. J Appl Meteorol 15: 43-49.

Wood CR and Järvi L (2012) An overview of urban climate observations in Helsinki. Magazine of the Finnish Air Pollution Prevention Society: 30-33

Wood CR, Kouznetsov RD, Gierens R, Nordbo A, Järvi L, Kallistratova MA and Kukkonen J (2013) On the Temperature Structure Parameter and Sensible Heat Flux over Helsinki from Sonic Anemometry and Scintillometry. J Atmos Ocean Technol 30: 1604-1615. doi: 10.1175/JTECHD-12-00209.1

Wood N and Mason P (1991) The influence of static stability on the effective roughness lengths for momentum and heat transfer. Q J R Meteorol Soc 117: 1025-1056. doi: 10.1002/qj.49711750108

Wyngaard JC (1973) On surface-layer turbulence. Workshop on micrometeorology, American Meteorological Society

Zieliński M, Fortuniak K and Pawlak W (2012) Turbulent sensible heat flux in Łódź obtained from scintillometer measurements - comparison of free and mix algorithms. Contempory Trends Geosci 1: 109-117.

Zilitinkevich SS, Mammarella I, Baklanov AA and Joffre SM (2008) The effect of stratification on the aerodynamic roughness length and displacement height. Boundary-Layer Meteorol 129: 179-190. doi: 10.1007/s10546-008-9307-9 